NBER WORKING PAPER SERIES

\title{
GOVERNMENT DISTORTION IN INDEPENDENTLY OWNED MEDIA: EVIDENCE FROM U.S. COLD WAR NEWS COVERAGE OF HUMAN RIGHTS
}

\author{
Nancy Qian \\ David Yanagizawa-Drott \\ Working Paper 15738 \\ http://www.nber.org/papers/w15738
NATIONAL BUREAU OF ECONOMIC RESEARCH
1050 Massachusetts Avenue
Cambridge, MA 02138
February 2010

This paper supersedes the previous version entitled, "Watchdog and Lapdog...". We are indebted to Matthew Gentzkow, Mikhail Golosov and David Stromberg for their many thoughtful comments; Abhijit Banerjee, Stefano DellaVigna, Raquel Fernandez, Dean Karlan, Brian Knight, Michael Kremer, Justin Lahart, Suresh Naidu, Nathan Nunn, Torsten Persson, Jesse Shapiro, Jakob Svensson and Chris Udry for their insights; and the seminar participants at Stanford University, Yale University, New York University, Boston University, the University College of London, Stockholm University IIES, Warwick University, Universitat de Pompeu Fabra, Paris School of Economics, Universitet du Toulouse, McGill University, NBER Summer Institute Political Economy, BEROC, BREAD CIPREE and NEUDC for useful comments; and Carl Brinton and Aletheia Donald for invaluable research assistance. All mistakes are our own. Comments or suggestions are very welcome. The views expressed herein are those of the authors and do not necessarily reflect the views of the National Bureau of Economic Research.

NBER working papers are circulated for discussion and comment purposes. They have not been peerreviewed or been subject to the review by the NBER Board of Directors that accompanies official NBER publications.

(C) 2010 by Nancy Qian and David Yanagizawa-Drott. All rights reserved. Short sections of text, not to exceed two paragraphs, may be quoted without explicit permission provided that full credit, including (C) notice, is given to the source. 
Government Distortion in Independently Owned Media: Evidence from U.S. Cold War News

Coverage of Human Rights

Nancy Qian and David Yanagizawa-Drott

NBER Working Paper No. 15738

February 2010, Revised September 2013

JEL No. L82,P16

\begin{abstract}
This paper investigates the extent to which strategic objectives of the U.S. government influenced news coverage during the Cold War. We establish two relationships: 1) strategic objectives of the U.S. government cause the State Department to under-report human rights violations of strategic allies; and 2) these objectives reduce news coverage of human rights abuses for strategic allies in six U.S. national newspapers. To establish causality, we exploit plausibly exogenous variation in a country's strategic value to the U.S. from the interaction of its political alliance to the U.S. and membership on the United Nations Security Council. In addition to the main results, we are able to provide qualitative evidence and indirect quantitative evidence to shed light on the mechanisms underlying the reduced form effects.
\end{abstract}

Nancy Qian

Department of Economics

Yale University

27 Hillhouse Avenue

New Haven, CT 06520-8269

and NBER

nancy.qian@yale.edu

David Yanagizawa-Drott

79 JFK Street

Cambridge, $02138 \mathrm{MA}$

USA

David_Yanagizawa-Drott@hks.harvard.edu 


\section{Introduction}

Mass media plays a powerful role in society. It reaches an immense audience, and its content can affect a wide range of outcomes, including political behavior such as voting. ${ }^{1}$ In democratic regimes such as the United States, the importance of the media is reflected in its being called the fourth estate, which is supposed to report on the activities of the government in the interest of the public and act as a "watchdog" of democracy. However, the ability of the media to perform its prescribed role has come under question as observers point to an increasing number of instances when media content is distorted by the government. Numerous books written by political scientists and former journalists voice this concern. Prominent examples include Bennett, Lawrence, and Livingston (2008), Cook (1998) and Thomas (2006). ${ }^{2}$ The examples of government distortion come from many different time periods, including the war with Vietnam during the 1960s, interventions in Central America during the 1980s, as well as the recent war with Iraq that began in 2003 (Bennett, Lawrence, and Livingston, 2008). Bennett, Lawrence, and Livingston (2008, p. 8) summarizes the motivation behind these concerns: "The democratic role of the press is defined.. by those moments when government deception or incompetence compels journalists to find and bring credible challenges to public attention and hold rulers accountable... This accountability function of the U.S. press has been weakened in the contemporary era, and its standing is sorely in need of greater examination". Similarly, in her textbook, Mass Media and American Politics, Graber (2006) urges a closer examination of the political economy of media with a quote from Joseph Pulitzer, "An able, disinterested, public-spirited press, with trained intelligence to know the right and courage to do it, can preserve that public virtue without which popular government is a sham and a mockery... The power to mould the future of the Republic will be in the hands of the journalists of future generations", to which Graber follows with, "How well is the U.S. press meeting [this challenge]?" Graber (2006, p.20). ${ }^{3}$

This paper attempts to make progress on this important question by assessing the extent of

\footnotetext{
${ }^{1}$ Recent studies have shown that media can affect voting behavior (e.g., Prat and Stromberg, 2005; Gentzkow, 2006; DellaVigna and Kaplan, 2007; Chiang and Knight, 2011; and Enikolopov and Zhuravskaya, 2011), other political behavior (Paluck, 2008; Gerber, Karlan, and Bergan, 2009; Olken, 2009), and social outcomes such as literacy (Gentzkow and Shapiro, 2008a) female empowerment (Jensen and Oster, 2009) and fertility (La Ferrara, Chong, and Duryea, 2008).

${ }^{2}$ See the works referenced in Bennett, Lawrence, and Livingston (2008) and Cook (1998) for the large body of work about the media and the U.S. government from media and political science scholars.

${ }^{3}$ The quote from Pulitzer was originally printed in the North American Review (1904).
} 
government distortion of the news in the United States. Our study aims to determine whether the anecdotal and case evidence on government manipulation reflects isolated incidents or whether they reflect systematic distortion that could be a symptom of deeper and more fundamental concerns. In other words, we ask whether a democratic government can systematically distort news coverage from independently owned outlets. With the exception of Besley and Prat (2006), this question has not yet been rigorously studied. ${ }^{4}$ For practical reasons that we discuss later, we focus on human rights news coverage during the latter period of the Cold War.

Our study proceeds in three steps. First, to motivate our investigation, we document that the U.S. government often attempted to manipulate news coverage of human rights practices of their political allies during the Cold War. We rely on qualitative evidence from political scientists as well as internal government memos that explicitly state government objectives and tactics for a large number of cases. These memos, which are typically not available to the public, were declassified as part of the Iran-Contra investigation. The availability of rich case evidence is the one of the advantages of focusing on the Cold War era.

Second, we combine the recent theories of endogenous news coverage developed by Prat and Stromberg $(2005,2011)$ and Stromberg $(1999,2004 a, 2004 b)$ with a theory of media manipulation by Besley and Prat (2006) to develop a framework for understanding government manipulation in our context. In our model, domestic voters care in part about the foreign policy pursued by the U.S. government. Voters cannot directly and fully evaluate the foreign policy (preferences) of the incumbent and partly base their inferences on the behavior of allied foreign countries that vote with the United States in the United Nations (UN). News reports about human rights violations of allies serve as indicators of U.S. foreign policy and affect the probability that the incumbent U.S. government will be voted out of office. We assume that "worse" countries are more likely to commit human rights violations and are more likely to vote with the United States if the U.S. government's foreign policy is "bad". U.S. voters observe voting behavior and read about human rights violations to make their inferences about the U.S. government's type. There are two groups of voters. The first group has broad interests, reads the news about all foreign countries and make inferences based on the behavior of all countries. The second group is only interested in the countries that are currently

\footnotetext{
${ }^{4}$ A recent working paper by Gentzkow, Petek, Shapiro, and Sinkinson (2012) examines the historical U.S. context. We discuss this study more later in the introduction.
} 
on the UNSC. That voters infer the quality of government policies from news reports and the insight that newspaper coverage affects the posterior beliefs of the voters about the quality of those policies is very similar to the framework in Durante and Knight (2012).

It follows that obtaining a seat on the Security Council generates two opposing effects on U.S. news coverage of the human rights practices of foreign countries: $i$ ) the demand effect, an increase in coverage when countries become Council members because more readers are interested; and ii) the distortion effect, a reduction in coverage due to the incentives of the government to manipulate the media. Since there are many fewer countries on the Council than not on the Council (e.g., in the UN General Assembly), it is cheaper for the U.S. government to manipulate public opinion by suppressing news about Security Council countries than non-Security Council countries. Moreover, we show that the closer the foreign country is aligned with the United States, the more severe the distortion on news coverage. Our model implies that if there is government distortion, then we should observe that the increase in news coverage that occurs with Council membership is declining in magnitude with the level of alliance. For strongly allied countries, Council membership can actually reduce the amount of news coverage.

The final and most important step in our paper is to estimate the differential relationship between Council membership and U.S. news coverage for foreign countries of different levels of alliance with the United States during the Cold War. We follow an earlier paper, Qian and Yanagizawa-Drott (2009) and proxy for alliance with the degree to which a country votes with the United States in the UN General Assembly on issues for which the United States votes in opposition to the Soviet Union during the end of the Cold War. ${ }^{5}$ Data on news coverage is collected from the text-analysis of five large U.S. newspapers (New York Times, Wall Street Journal, Washington Post, Chicago Tribune and Los Angeles Times).

We examine the interaction effect of a time-invariant measure of Cold War alliance with the U.S. and a time-varying measure of Council membership, while controlling for year and country fixed effects. Country fixed effects control for all time-invariant characteristics across countries such as cultural affinity with the United States, which can affect the degree of alliance, Council membership and/or news coverage. Year fixed effects control for all changes over time that influence

\footnotetext{
${ }^{5}$ Qian and Yanagizawa-Drott (2009) studies the relationship between political alliance with the United States and human rights abuses reported by the U.S. State Department and Amnesty International. This earlier work does not examine media news coverage or the United Nations Security Council.
} 
all countries equally. The coefficient of the interaction term reveals the degree to which Council membership differentially influences the news coverage of countries with higher levels of alliance and the coefficient of the uninteracted Council membership term reveals the effect of Council membership for the least allied countries with the United States in our sample. In the context of our framework, finding a negative interaction would be consistent with the presence of government distortion, and a positive coefficient for the uninteracted Council membership variable would be consistent with the presence of the demand effect. These two forces are not mutually exclusive.

The results indicate that news coverage of human rights abuses of foreign countries during the Cold War was influenced by both government distortion and reader demand. Taken literally, our estimates imply that Council membership for a country that is on the 75th percentile of the distribution of U.S. alliance (e.g., Ecuador, Egypt) will result in approximately $40 \%$ fewer news articles about human rights abuses than Council membership for a country that is on the 25th percentile of the distribution of alliance (e.g., Mali, the Republic of Congo).

Our results are consistent with U.S. news coverage being partly determined by government distortions and partly driven by reader demand. This interpretation relies on the assumption that there were no other forces that were simultaneously correlated with news coverage, Council membership and political alliance with the United States. We do not take this as given and provide a large body of evidence in support of our interpretation. For example, we show that the timing of our reduced form effects corresponds with entry onto and exit from the Council. We also show that our estimates are robust to controlling for a large number of potentially confounding factors such as the interactions of the full vector of year fixed effects with variables such as Council membership and U.S. alliance. See the section 6 for a detailed discussion.

In addition, we provide several pieces of evidence to support our interpretation of the main results. First, we show that the response of annual U.S. State Department reports of human rights abuses of foreign countries to the interaction of alliance with the U.S. government and UNSC membership is very similar to that of news coverage, which is consistent with our interpretation that the interaction effect captures the influence of U.S. government manipulation. In contrast, reports from Amnesty International, a non-government organization, do not respond to the interaction of UNSC and U.S. alliance. This goes against the alternative explanation that our results reflect changes in actual human rights practice. Second, we show that the interaction term of U.S. alliance 
and UNSC membership has no effect on a large number of institutional measures that may be correlated with human rights practices. This again goes against the alternative explanation that the results on news coverage and U.S. State Department reports are driven by changes in actual human rights behavior. Fourth, when we estimate the interaction effect for each newspaper, we find that there is no correlation between the degree of distortion and reader preferences across papers. While this should be interpreted very cautiously because there are only five newspapers, the results are consistent with our interpretation that the interaction effects do not capture reader preferences. In contrast, we find that the magnitude of distortion is positively correlated with newspaper quality and reputation, which is straightforward to reconcile with our framework and that of Besley and Prat (2006). Finally, we show that Council membership has no effect on news coverage after the Cold War for any country. Amongst other explanations, this is consistent with the belief that the U.S. government's motivation for manipulating news of Cold War allies declined with the end of the Cold War.

For policymakers, our results confirm the case evidence that systematic government-driven distortions can exist for independently owned and highly competitive media outlets in a democratic regime. At the same time, one may view the fact that our effects dissipate with the end of the Cold War as reassuring - i.e., it may be difficult for systematic manipulation to last indefinitely in such contexts. We speculate on this more in the conclusion.

In our focus on the government's influence of media coverage, our study is most closely related to Besley and Prat (2006). It also builds directly on the pioneering work of Besley and Prat (2006), Durante and Knight (2012), Prat and Stromberg (2005, 2011) and Stromberg (1999, 2004a, 2004b) by adapting the frameworks developed in these papers and applying them to a novel empirical context. To the best of our knowledge, our paper is the first to provide rigorous evidence that government distortion has systematically existed in the United States. In doing so, we add to the important empirical literature on the determinants of news coverage. Our study differs from previous studies in focusing on government-driven distortions in a democratic regime. In this sense, we are related to two recent studies about the effect of partisan-controlled media in Italy under Berlusconi (Durante and Knight, 2012) and the United States during 1869-1928 (Gentzkow, Petek, Shapiro, and Sinkinson, 2012). The former study finds evidence of government influence on the media in the modern Italian context, while the latter study finds that the government in power has 
little influence over news composition in the historical U.S. context.

Second, we add to the small but growing number of political economy studies that explore the causes and consequences of U.S. government foreign policy. In our focus on the Cold War era, our study is most closely related to Dube, Kaplan, and Naidu's (2011) study of U.S. covert actions on U.S. firm stock prices, and Berger, Easterly, and Satyanath's (2009) and Berger, Easterly, Nunn, and Satyanath's (2010) studies of U.S. Cold War policies on trade. It broadens the scope of this literature by examining the effect of U.S. foreign policy on the American public. Finally, our use of United Nations Security Council membership as a proxy for a country's importance to the United States borrow's from Kuziemko and Werker's (2006) insight that Council membership plays an important role in the behavior of the U.S. government. Similarly, our use of voting in the UN General Assembly as a proxy of U.S. alliance follows Alesina and Dollar (2000), which find that voting with the U.S. in the General Assembly is positively correlated with U.S. foreign aid receipts. ${ }^{6}$

This paper is organized as follows. Section 2 discusses the background. Section 3 presents the conceptual framework. Section 4 presents the empirical strategy. Section 5 describes the data. Section 6 presents the main empirical results. Section 7 presents additional, more speculative, results. Section 8 offers concluding remarks.

\section{Background}

\section{1 "White Propaganda" During the Cold War}

The main period of our study, 1976-1988, was characterized by a commitment to fight communism on the part of the American government, which climaxed during the Reagan administration (1980-88). As with all of the Cold War, rivalry between the two superpowers was expressed through military coalitions, propaganda and proxy wars (e.g., the Soviet war in Afghanistan 1979-89). The Cold War ended during 1989-91 when the Berlin Wall fell and the U.S.S.R. dissolved. For the purposes of our paper, we loosely interpret 1989 as the end of the Cold War. At this time, the strenuous competition between the United States and the U.S.S.R. for the alliance of smaller countries ended.

An important feature of the Cold War in the United States was the focus on the superior morality of the West. The U.S. government and news media often described its allies as "good"

\footnotetext{
${ }^{6}$ Kuziemko and Werker (2006) finds that Council membership in years that are strategically important for the U.S. government results in higher U.S. aid. They cleverly measure importance with the number of articles in the New York Times about the Security Council.
} 
and the Eastern Bloc and its allies as "evil". Recently declassified files stored in the U.S. National Security Archives document both the method and the motives for the U.S. government to influence the press coverage of the human rights practices of its political allies.

The government needed public support for its political actions, which included public approval of its political allies. Given the focus on morality, it followed that U.S. allies should have better human rights abuses than Eastern Bloc allies. ${ }^{7}$ For the most part, U.S. government support for its Cold War allies with poor human rights abuses ended with the Cold War. Internal memos show that the executive branch believed that one of the ways to shape public opinion against opponents was to exaggerate human rights abuses in those countries and emphasize that amongst other things, they were "evil", "forced conscription" or engaged in the "persecution of the church". Conversely, the government attempted to increase support for political allies by calling them "freedom fighters", "religious" or simply "good" (Jacobwitz, 1985b).

The task of influencing press coverage was officially delegated to the Office of Public Diplomacy (OPD) during the Reagan administration. The OPD was part of the State Department and worked closely with the National Security Council (NSC). Its explicit purpose was to influence public and congressional opinion to garner support for the President's strong anti-communist agenda in a "public action" program (Parry and Kornblub, 1988). The memo specifies that audiences for the information campaign include the U.S. media (Jacobwitz, 1985b).

"..we can and must go over the heads of our Marxist opponents directly to the American people. Our targets would be within the United States... the general public [and] media." - Kate Semerad, an external relationship official at the Agency for International Development (AID) in 1983.

Government methods for influencing the media can be broadly categorized into two groups. First, the government can attempt to directly manipulate news reports by exerting pressure on editorial boards or incentivizing journalists. The OPD monitored news reports by the American media and would directly confront journalists and editors in order to convince them to change the reports

\footnotetext{
${ }^{7}$ For studies on U.S. government favoritism of human rights reports of its Cold War allies, see studies such as Carleton and Stohl (1985), Mitchell and McCormick (1988), Poe and Vazquez (2001), and Qian and YanagizawaDrott (2009).

In the case of the The New York Times, which published an international version under the title of The International Herald Tribune, manipulation could also affect the opinion of foreign readers. Also, influencing the press could also affect congressional opinion, whose favor was often necessary for legislative purposes (Blanton and Blanton, 2007).
} 
(Schultz, 2001). Upon the appearance of news reports that did not conform to the wishes of the OPD, officials could press the owners and editorial boards to change their journalists in the field. The OPD also dealt directly with journalists using a carrot-and-stick strategy. For example, uncooperative journalists became the targets of character assassination meant to induce skepticism about the information they reported and were sometimes even forcibly removed from foreign countries from which they were reporting. ${ }^{8}$ In contrast, journalists seen as cooperative to the administration's agenda were rewarded with increased access to government information. For example, an OPD memo stated that certain favorable correspondents had "open invitations for personal briefings" (Cohen, 2001). ${ }^{9}$

Second, the government can manipulate the supply of information and provide disinformation. Information can be disseminated through the numerous government affiliated publicity events and publications. One such publication is the Country Reports on Human Rights Practices, which we will discuss later in the paper. In a letter to House Speaker Patrick Buchanan, the Deputy Director for Public Diplomacy for Latin American and the Caribbean (SLDP), Jonathan Miller, described how the OPD was carrying out "white propaganda" operations. This included writing opinion articles under false names and placing them in leading newspapers such as the Wall Street Journal (Hamilton and Inouye, 1987; Miller, 2001). Similar opinion editorials were planted in the New York Times and the Washington Post (Brooks, 1987). The OPD paid extra attention to prominent journalists. In general, the OPD flooded the media, academic institutions and other interested groups with information. For example, in 1982, the OPD booked more than 1,500 speaking engagements with editorial boards, radio, and television interviewers, distributed materials to 1,600 college libraries, 520 political science faculties, 122 editorial writers, and 107 religious groups (Parry and Kornblub, 1988).

\subsection{The United Nations}

The United Nations (UN), a source of much of the diplomatic influence and the principal outlet for the foreign relations initiatives of non-superpower countries, was especially important during the

\footnotetext{
${ }^{8}$ One famous case was the removal of New York Times reporter Raymond Bonner from El Salvador after his unfavorable reporting of the massacre by the Salvadoran government. The U.S government pressured the NYT to recall Bonner (Parry and Kornblub, 1988). Other outlets such as the Wall Street Journal subsequently published articles criticizing the NYT for publishing Bonner's reports.

${ }^{9}$ Blanton and Blanton (2007) provides an overview of all the actions taken by the Office for Public Diplomacy (OPD) during the Reagan Administration (1980-88). For detailed accounts of when the media allows the government to distort reports, see Bennet, Bennet and Livingston (2007) and Thomas (2006).
} 
Cold War. ${ }^{10}$ Two of the five principal organs of the UN are the General Assembly and the Security Council (UNSC). During the period of our study, there were approximately 150 member countries, of which more than two-thirds were developing countries. The General Assembly votes on many resolutions brought forth by sponsoring states. Most resolutions, while symbolic of the sense of the international community, are not enforceable as a legal or practical matter. The General Assembly does, however, have authority to make final decisions in areas such as the UN budget, and in case of a split vote in the Council when no veto is exercised, the issue goes for a vote in the General Assembly.

The Security Council is comprised of fifteen member states. Hence, it is significantly smaller than the General Assembly. Council members have more power than General Assembly members because the Council can make decisions which are binding for all UN member states, including economic sanctions and the use of armed force (Chapter Seven of the UN Charter). There are ten temporary seats that are held for two-year terms, each one beginning on January 1st. Five are replaced each year. The members are elected by regional groups and confirmed by the UN General Assembly. New members are typically announced the year before the term begins. ${ }^{11}$ There are five permanent members (P5): China, France, Russia, the United Kingdom and the United States. These members hold veto power for blocking adoption of a resolution. Experts vary in their assessment of the power of rotating members over important issues during our period of study. On the one hand, rotating members cannot overturn vetoes and some political scientists argue that they have limited real power (e.g., O’Neill, 1996). On the other hand, studies such as Voeten (2001) argue that P5 countries prefer multilateral agreements, which, in turn, gives much power to rotating members. For example, deadlocks on the Council can only occur if there is no veto and nine of the ten deadlocks that have ever occurred in the history of the UN occurred during the Cold War. ${ }^{12}$

\footnotetext{
${ }^{10}$ For a detailed discussion of the history and institutions of the United Nations, see Malone (2004).

${ }^{11}$ Africa elects three members; Latin America and the Caribbean, Asian, and Western European and others blocs choose two members each; and the Eastern European bloc chooses one member. Also, one of these members is an Arab country, alternately from the Asian or African bloc. Members cannot serve consecutive terms, but are not limited in the number of terms they can serve in total. There is often intense competition for these seats (Malone, 2000).

121956 Suez Crisis; 1956 Soviet Invasion of Hungary (Hungarian Revolution); 1958 Lebanon Crisis; 1960 Congo Crisis; 1967 Six Days War; 1980 Soviet invasion of Afghanistan; 1980 Israeli-Palestinian Conflict; 1981 South African occupation of Namibia (South West Africa); 1982 Israeli Occupation of the Golan Heights (Golan Heights Law); 1997 Israeli-Palestinian conflict (East Jerusalem and Israeli-occupied territories).
} 


\section{Model}

In this section, we develop a framework of how alliance with the U.S. government and membership on the United Nations Security Council can interact to affect U.S. news coverage of human rights abuses of foreign countries. Specifically, our framework studies the incentives of the government to distort media coverage of state repression in foreign countries. In our model, domestic voters care in part about the foreign policy that the U.S. government pursues, but voters cannot directly and fully evaluate the foreign policy (preferences) of the incumbent. Voters partly base their inferences on the behavior of allied foreign countries that vote with the United States in the UN. News reports about human rights violations of the allies serve as indicators of U.S. foreign policy, which affects the probability that the incumbent U.S. government will be voted out of the office.

Before presenting the formal model, we sketch the basic intuition behind it. In our model, "worse" countries are more likely to commit human rights violations and are more likely to vote with the United States if the U.S. government's foreign policy is bad. U.S. voters observe voting behavior and read about human rights violations to make their inferences about the U.S. government's type. There are two groups of voters. The first group is interested in and reads the news about all foreign countries. As a result, voters in the first group make inferences based on the behavior of all countries. The second group is interested only in the countries that are currently on the UNSC. We do not formally model the reason for this. This assumption is motivated by the fact that the Council discusses more important issues and/or has more power over these issues. Alternatively, it could simply be because being on the Security Council acts as a focal point for readers with limited interest in foreign policy. The second group solely bases its inferences on the news coverage of Council members.

In our model, obtaining a seat on the Security Council generates two effects on news coverage. The first is a demand effect. As a country becomes a member of the Council, more people are interested in reading about it. In the absence of government interference, newspapers would then increase their coverage of human rights abuses in these countries. The second effect is a distortion effect that comes from the incentives of the government to manipulate the media. We show that if the

number of countries not on the Council is much larger than the number of countries on the Council 
(e.g., the General Assembly), it is much cheaper for the U.S. government to manipulate public opinion by suppressing news about Security Council countries than non-Security Council countries. Because voters in the first group based their inferences on voting and human right violations of all countries, distorting news coverage about one of them has little effect on the posterior beliefs of this group when the total number of countries is large. In contrast, the voters in the second group base their inferences on the voting behavior of a relatively small number of countries on the Council, and the distortions in the coverage of one country has a large effect on the voters' posterior beliefs about the U.S. government's type. As a result, when the country enters the Council, it is optimal for the U.S. government to significantly intensify its distortion of news coverage. Moreover, this effect is monotone. The closer the foreign country is aligned with the United States, the more severe the distortion will be.

Methodologically, our approach combines recent theories of endogenous news coverage developed by Prat and Stromberg $(2005,2011)$ and Stromberg (1999, 2004a, 2004b) with a theory of media manipulation by Besley and Prat (2006). That voters in our model try to infer the quality of the government policies from news reports and that newspaper coverage affects the posterior beliefs of the voters about the quality of those policies is very similar to Durante and Knight (2012). ${ }^{13}$ The ultimate goal of our model is to derive testable implications to guide the empirical investigation of whether there is government distortion in the context that we study.

\subsection{Setup}

Our model of media coverage is a close adaptation of Prat and Stromberg (2011, section 5), and we mostly follow their notation. We consider a simple two-period model with no discounting. An incumbent U.S. government has type $\theta_{U S}$, which is the same in both periods. In the end of period one, U.S. voters decide whether to keep the incumbent or replace it with a challenger. Both the incumbent's and the challenger's types are drawn from a uniform distribution which takes values on $[0,1]$. Neither type is observed directly by voters. Voters make inferences about the incumbent's type from the U.S. government's voting record in the UN General Assembly and from news coverage of U.S. allies in the UN. Higher $\theta_{U S}$ corresponds to the U.S. government being "better" from the point of the of domestic voters.

\footnotetext{
${ }^{13}$ Durante and Knight (2012) studies the optimal choice of news outlet based on their ideological leaning. We abstract from the differences in ideology and focus on the incentives of the government to manipulate news coverage.
} 
There are four main groups of players in our model: the U.S. government, foreign governments, U.S. voters and the U.S. media. We discuss each of these groups in turn.

\subsubsection{U.S. government}

The U.S. government cares about two objectives: $i$ ) passing the foreign policy issue that it favors in the UN, and ii) rents associated with being in office. It has two instruments at its disposal to achieve its goals. The first instrument is its vote on a given issue. The second is the distortion of newspapers to get favorable coverage. We assume that the U.S. government votes sincerely and focuses on the incentives to distort the news coverage. ${ }^{14}$

\subsubsection{Foreign governments}

We assume that there are $N+1$ foreign countries and each country $n$ can be one of the two types, either "bad" $\left(\theta_{n}=0\right)$ or "good" $\left(\theta_{n}=1\right)$. For concreteness, we assume that each country's type is drawn ex-ante independently and is equally likely to take either type. In the UN, the U.S. and foreign countries vote on a large number of resolutions. Each issue, $x_{j}$, takes a value which is being drawn from a uniform distribution on $[0,1]$. The payoff for a country of type $k \in\{0,1, U S\}$ if the resolution $j$ is passed is

$$
\left(\frac{1}{4}-\left(x_{j}-\theta_{k}\right)^{2}\right)
$$

The payoff if a resolution is not passed is normalized to zero.

Under the assumption that countries vote sincerely, this convenient formalization means that the U.S. votes with a country of type $\theta_{k}=0$ with probability $1-\theta_{U S}$ and with a country of type $\theta_{k}=1$ with probability $\theta_{U S}$. Since we assume that the number of resolutions is large, the observed frequency of voting with country $k$ reveals the degree of alliance with the United States, $A_{U S, k}=\left|\theta_{U S}-\theta_{k}\right|$, perfectly.

Out of $N+1$ foreign countries, one is randomly selected to be on the Council. Without any loss of generality, we denote this country by $n=N+1$. In this model, the only distinction between being and not being on the Council is that more U.S. voters will be interested in reading the news about countries on the Council. ${ }^{15}$

\footnotetext{
${ }^{14}$ It is possible to extend this model to account for strategic voting by the U.S. and show that the main insights continue to hold in that case. This extension is available upon request.

${ }^{15}$ One can make the case that, in general, more information will be revealed about a country's type when it is on the Security Council, for example, because policy deliberations generally reflect more important issues. Such mechanisms will generally strengthen the effect we consider in this model.
} 
Foreign governments of type $\theta_{n}=0$ are repressive and commit human rights abuses. Governments of type $\theta_{n}=1$ are not repressive and do not abuse human rights.

\subsubsection{U.S. Voters}

U.S. voters do not observe foreign governments' types or the U.S. government's type directly. Voters read newspapers and they become informed about the type of the foreign government and how closely it is allied with the United States with some probability. We assume that there are two groups of voters. Group 1 reads news about all foreign countries. Group 2 reads only about foreign countries that are "powerful", i.e., on the UN Security Council. ${ }^{16}$ Let $m_{1}$ and $m_{2}$ be the strictly positive fraction of voters in groups 1 and 2, respectively.

In the next section, we describe how voters become informed. Based on media coverage, some fraction $s$ of the population becomes informed about human rights violations of foreign governments and how frequently that government voted with the United States. Both pieces of information, therefore, perfectly reveal the type of the incumbent, $\theta_{U S}$. A fraction, $1-s$, remains uninformed, and their posterior beliefs about the incumbent type remains unchanged, with the expected value of $1 / 2$.

The expected utility from keeping the incumbent in office in period 2 is $\mathbb{E}\left[\theta_{U S}\right]$, where $\mathbb{E}$ is the expectation given the information that each voter has. The utility from selecting the challenger is $\mathbb{E}\left[\theta_{U S}^{\prime}\right]+\delta$, where $\mathbb{E}\left[\theta_{U S}^{\prime}\right]$ is the expected challenger's type and $\delta$ is an idiosyncratic characteristic of the challenger. We assume that $\delta$ is uniformly distributed on $[-1 / 2,1 / 2]$.

For brevity, we focus on sincere voting. Since $\theta_{U S}^{\prime}$ is drawn from the same distribution as $\theta_{U S}$, the uninformed voters vote for the incumbent if $-\delta \geq 0$, which occurs with probability $1 / 2$. The informed agents vote for the U.S. government if $\theta_{U S}-1 / 2-\delta \geq 0$. The $\delta$ to satisfy this condition is realized with probability $\theta_{U S}$. Therefore, the probability of re-election of the incumbent, $\mu$, is

$$
\mu=s \theta_{U S}+(1-s) \frac{1}{2}
$$

We study how voters become informed in the following section.

\footnotetext{
${ }^{16}$ As in Prat and Stromberg (2011), one can allow for an arbitrary number of groups and issues that are policyrelevant. We focus on foreign news given the nature of the data in the empirical section, but the main implications of the model are potentially applicable to domestic news as well.
} 


\subsubsection{Mass Media}

We now consider the media market. The main idea is that bigger news coverage about any country increases the fraction of voters informed about it. We follow the arguments of Prat and Stromberg $(2005,2011)$ and Stromberg $(1999,2004 a, 2004 b)$. Let $q_{n}$ be the amount of news coverage for country $n$. A reader buys the newspaper based on the amount of coverage and on idiosyncratic characteristics. The reader knows that if he buys a newspaper with $q_{n}$ stories about country $n$, he will find the news to be entertaining and the information to be relevant with probability $\rho\left(q_{n}\right)$, where $\rho$ is an increasing function. If the reader finds the information entertaining, he obtains 1 unit of utility. Let $\varepsilon_{i}$ be the reader's exogenous idiosyncratic valuation of newspapers, which is uniformly distributed on $[0,1]$. If the price of the newspaper is $p$, the reader buys it if

$$
\rho\left(q_{n}\right)-\varepsilon_{i} \geq p
$$

For simplicity, we assume that $\rho(q)=q$ and the parameters of the model are such that in equilibrium, $q \leq 1$. Thus, if the newspaper has $q_{n}$ news about country $n$, the probability that a reader is interested in country $n$ is $\max \{q-p, 0\}$. Once a reader buys the newspaper, he learns that $\theta_{n}=1$ and the degree of alliance of that country with the United States, $A_{U S, n}$, which is sufficient for inferring the true type of the U.S. government, $\theta_{U S}$.

As in Prat and Stromberg (2005, 2011), we assume that newspapers operate an increasing returns to scale technology, since there are costs of gathering news and writing a story which is independent of the number of newspaper copies sold. We assume that news cannot be fabricated, and it is therefore impossible to write about human rights violations for countries for which $\theta_{n}=1$. For countries that commit human right violations $\left(\theta_{n}=0\right)$, newspapers select the optimal amount of coverage. The cost of publishing $q_{n}$ stories is

$$
\frac{\gamma}{2} q_{n}^{2}+\tilde{m}\left(q_{n}-p\right) d
$$

where $d$ reflect the cost of distribution, $\gamma>0$ is a parameter, and $\tilde{m}=m_{1}+m_{2}$ for a country on the Security Council and $\tilde{m}=m_{1}$ for any other foreign country. Here, the first term is the fixed cost that is independent of the number of copies and the second term represents constant marginal costs, 
$d$, which are proportional to the demand for newspaper, $\tilde{m}\left(q_{n}-p\right)$. The profit for the newspaper from publishing $q_{n}$ news is then

$$
\Pi\left(q_{n}\right)=(p-d) \tilde{m}\left(q_{n}-p\right)-\frac{\gamma}{2} q_{n}^{2}
$$

For simplicity, we assume that there is only one newspaper and that $p$ is exogenous and greater than $d$. Both of these assumptions can be relaxed along the lines suggested by Stromberg (2004a, 2004b).

Before we characterize the equilibrium with news manipulation, it will be informative to describe the equilibrium when the government does not interfere. In this case, the optimal news coverage $\hat{q}_{n}$ maximizes (3) for each $n$ for which $\theta_{n}=0$. It is straightforward to see that $\hat{q}_{n}$ satisfies

$$
\hat{q}_{n}=\left\{\begin{array}{cc}
0 & \text { if } \theta_{n}=1 \\
\frac{1}{\gamma}(p-d) m_{1} & \text { if } \theta_{n}=0 \text { and } n \leq N \\
\frac{1}{\gamma}(p-d)\left(m_{1}+m_{2}\right) & \text { if } \theta_{n}=0 \text { and } n=N+1
\end{array} .\right.
$$

This implies that news coverage of human rights abuses is higher if the country joins the Council. To make sure that $\hat{q}_{n}-p$ are well defined probabilities when $\theta_{n}=0$, we assume that $\left(p, d, m_{1}, m_{2}, \gamma\right)$ jointly satisfy

$$
\begin{aligned}
\frac{1}{\gamma}(p-d) m_{1}-p & >0 \\
\frac{1}{\gamma}(p-d)\left(m_{1}+m_{2}\right) & <1 .
\end{aligned}
$$

To find the probability with which the U.S. incumbent retains power, we need to find the number of informed voters. We start with group 2. In the context of our model, if the country on the Security Council does not commit any human rights violations, then no news coverage is available and all voters in group 2 retain their prior beliefs that the probability that the U.S. government is of type 1 is $0.5 .{ }^{17}$ If the country committed human rights violations, then fraction $\frac{1}{\gamma}(p-d)\left(m_{1}+m_{2}\right)-p$

\footnotetext{
${ }^{17}$ In principle, the lack of news about country $n$ can be an informative signal about country $n$, since in our model, all news is assumed to be bad news. For simplicity, we assume that readers update their beliefs about country $n$ (and about the U.S. government) only if they read the news about this country and if they find the news entertaining. In a richer model in which good news can be generated about good countries, this issue does not arise and the analysis of that model is very similar to the one presented in this section. Since our empirical strategy allows us to identify
} 
of voters in group 2 will see the news and learn that the true type of the U.S. government is $\theta_{U S}$. The fraction $1-\left(\frac{1}{\gamma}(p-d)\left(m_{1}+m_{2}\right)-p\right)$ remains uninformed and retain the prior that the U.S. government is of type 1 with probability 0.5 .

Next, we turn to voters in group 1. A voter learns the type of the U.S. government if she spots news coverage for at least one country. Suppose that out of the $N$ countries, $\tilde{N}$ commit human rights violations and the country on the security council is also type $\theta_{N+1}=0$. Then the probability that she does not spot any news coverage is and retains her prior belief is

$$
\begin{aligned}
& \left(1-\max \left\{\rho\left(\hat{q}_{1}\right)-p, 0\right\}\right) \times \ldots \times\left(1-\max \left\{\rho\left(\hat{q}_{N+1}\right)-p, 0\right\}\right) \\
= & \left(1-\left(\frac{1}{\gamma}(p-d) m_{1}-p\right)\right)^{\tilde{N}}\left(1-\left(\frac{1}{\gamma}(p-d)\left(m_{1}+m_{2}\right)-p\right)\right) .
\end{aligned}
$$

Then the total share of informed voters who learn the type of the U.S. government, $s$, is

$$
\begin{aligned}
s= & \left(1-\left(1-\left(\frac{1}{\gamma}(p-d) m_{1}-p\right)\right)^{\tilde{N}}\left(1-\left(\frac{1}{\gamma}(p-d)\left(m_{1}+m_{2}\right)-p\right)\right)\right) m_{1} \\
& +\left(\frac{1}{\gamma}(p-d)\left(m_{1}+m_{2}\right)-p\right) m_{2} .
\end{aligned}
$$

Note that this pins down the probability of the U.S. incumbent retaining power, as given by (2).

\subsubsection{Equilibrium with manipulation}

Next, we turn to describing the equilibrium with manipulation. We keep the basic structure of the game the same as before. We introduce one more stage, following the logic of Besley and Prat (2006), in which the U.S. government can offer a transfer $T\left(\Delta_{n}\right)$ to the newspaper and suppress $\Delta_{n}$ news from publication. ${ }^{18}$ The newspaper can either reject the transfer and publish its profitmaximizing news quantity or accept it and publish at most $q_{n}$. We keep the rest of the model as above.

Let $s\left(\left\{q_{n}\right\}_{n=1}^{N+1}\right)$ be the fraction of voters who are informed if country $n$ has $q_{n}$ reports of human rights abuses. Suppose that $R$ is the value of the incumbent to remain in power, which is strictly

only bad news, we focus on this simpler set up.

${ }^{18}$ As in Besley and Prat (2006), the bribe that the U.S. government pays to a newspaper is not necessarily a monetary transfer, but can be different forms of non-pecuniary benefits that affect newspaper profits, such as offering exclusive interviews with the incumbent or leaking valuable political information to the newspaper. 
positive. Then the incumbent solves

$$
\max _{\left\{q_{n}\right\}_{n=1}^{N+1}}\left[s\left(\left\{q_{n}\right\}_{n=1}^{N+1}\right) \theta_{U S}+\left(1-s\left(\left\{q_{n}\right\}_{n=1}^{N+1}\right)\right) \frac{1}{2}\right] R-\sum_{n=1}^{N+1} T\left(\hat{q}_{n}-q_{n}\right)
$$

subject to

$$
T\left(\hat{q}_{n}-q_{n}\right)+\Pi\left(q_{n}\right) \geq \Pi\left(\hat{q}_{n}\right) \text { for all } n
$$

and

$$
q_{n} \leq \hat{q}_{n} .
$$

Here, the first constraint is a best response for the newspaper that agrees to suppress $\Delta_{n}=\hat{q}_{n}-q_{n}$ news only if its profits from doing so exceed the profits from rejecting the offer. The second constraint ensures that the newspaper cannot publish more news than the newspaper had originally planned and, in particular, that no human rights violation stories can be fabricated for countries $\theta_{n}=1$.

This problem is, in general, not well behaved. Function $s$ is neither concave nor convex, which makes the analysis harder. The problem simplifies when we focus on the empirically relevant case when the number of countries is large. In this case, it is easy to show that it is (approximately) not optimal to distort countries that are not on the Security Council. The reason for this is as follows. Note that the probability that a voter in group 1 is not informed about the type of the U.S. government is $\left(1-\max \left\{\rho\left(q_{1}\right)-p, 0\right\}\right) \times \ldots \times\left(1-\max \left\{\rho\left(q_{N+1}\right)-p, 0\right\}\right)$. When $N$ is large, so is the number of countries which violate human rights, $\tilde{N}$. If the probability that newspapers report human rights violation for such countries is positive, $\max \left\{\rho\left(q_{n}\right)-p, 0\right\}>0$, the fraction of uninformed types in group 1 becomes very small. The only way to substantially change the fraction of informed is to significantly suppress news for a large number of countries, which becomes prohibitively costly for a large $N$.

Formally, let $\left\{q_{n}^{*}\right\}_{n=1}^{N+1}$ be the equilibrium quantities of news that are a solution to (5). We have the following result, which we formally prove in the Appendix.

Lemma 1 Suppose $N$ is large. Then $q_{n}^{*} \approx \hat{q}_{n}$ for $n=1, \ldots, N$

Next, we focus on the distortion of news for a foreign country on the Council. Let $s_{1}\left(\left\{q_{n}\right\}_{n=1}^{N+1}\right)$ and $s_{2}\left(q_{N+1}\right)$ be the fraction of informed citizens in groups 1 and 2 . When $q_{N+1}^{*}$ is interior, the 
first order condition for $q_{N+1}^{*}$ is

$$
\left[\frac{\partial}{\partial q_{N+1}} s_{1}\left(\left\{q_{n}^{*}\right\}_{n=1}^{N+1}\right)+\frac{\partial}{\partial q_{N+1}} s_{2}\left(q_{N+1}^{*}\right)\right]\left(\theta_{U S}-\frac{1}{2}\right) R+(p-d)\left(m_{1}+m_{2}\right)=q_{N+1}^{*}
$$

For the reasons explained in the proof of Lemma 1, as $N \rightarrow \infty, \frac{\partial}{\partial q_{N+1}} s_{1}\left(\left\{q_{n}^{*}\right\}_{n=1}^{N+1}\right) \rightarrow 0$ and therefore for large $N$, we can ignore this term. Since $s_{2}\left(q_{N+1}\right)=m_{2}\left(q_{N+1}-p\right)$, the above expression becomes

$$
q_{N+1}^{*}=(p-d)\left(m_{1}+m_{2}\right)+\left(\theta_{U S}-\frac{1}{2}\right) R m_{2} .
$$

Since $q_{N+1}^{*} \leq \hat{q}_{N+1}$, this condition holds only for $\left(\theta_{U S}-\frac{1}{2}\right) \leq 0$. For $\left(\theta_{U S}-\frac{1}{2}\right)>0$, the optimal news suppression is zero, $q_{N+1}^{*}-\hat{q}_{N+1}=0$.

This result allows us to compare news coverage of a country on the Council and an identical country not on the security council. If this country is of type 1 , there is obviously no news coverage of human rights violations in any case. If the country is of type 0 , the difference in coverage $\Delta$ is given by

$$
\Delta=\underbrace{(p-d) m_{2}}_{\text {demand effect }}-\underbrace{\max \left\{\left(\frac{1}{2}-\theta_{U S}\right) R m_{2}, 0\right\}}_{\text {distortion effect }} .
$$

This formula shows that news coverage is determined by two effects when a country gets on the Security Council. The "demand effect" leads to an increase in coverage since more people want to read about the country on the Security Council. The "distortion effect" leads to a decrease in coverage for allies that violate human rights. Moreover, the closer the United States is allied to the foreign country (i.e., the lower $\theta_{U S}$ ), the stronger this effect will be. Since distortion occurs if $\theta_{U S} \leq \frac{1}{2}$ and the foreign country on the Security Council is of type 0, which happens with joint probability $1 / 4$, in expectation the distortion effect is positive. We summarize these findings in the theorem

Theorem 2 For a repressive country not allied with the United States, news coverage of its human rights violations increases when it enters the Security Council. The magnitude of the increase declines with the degree of alliance. If the benefit of being in power, $R$, is sufficiently large, then news coverage falls for close allies when they enter the Council.

The empirical analysis investigates whether these relationships are present in the data. 


\section{Empirical Strategy}

The relationship between news coverage, U.S. alliance and Council membership can be characterized as the following:

$$
Y_{i t}=\beta\left(A_{i} \times C_{i t}\right)+\alpha C_{i t}+\theta X_{i t}+\gamma_{i}+\delta_{t}+\varepsilon_{i t},
$$

where the outcome variable, news coverage of human rights abuses, in country $i$ in year $t, Y_{i t}$, is a function of: the interaction of alliance to the United States, $A_{i}$, and membership on the Security Council, $C_{i t}$; the uninteracted term for Council membership; a vector of country-year specific controls, $X_{i t}$; year fixed effects, $\delta_{t}$; and country fixed effects, $\gamma_{i}$. The standard errors are clustered at the country level to adjust for serially correlated shocks within countries. The country fixed effects control for all time-invariant differences across countries. Year fixed effects control for changes over time that affect all countries similarly. $X_{i t}$ includes a vector of country-year controls, which will be motivated and discussed later as they become relevant. Note that our measure of alliance is time-invariant and collinear with country fixed effects. Therefore, we do not control for the uninteracted alliance term in the baseline regression.

Our strategy is conceptually similar to a differences-in-differences (DD) strategy. We compare outcomes for countries when they are on the Council to when they are not, between countries that are strongly allied to the United States to those that are less allied. $\alpha$ is the association of Council membership and news coverage for foreign countries that are not allied to the United States at all, $A_{i}=0 . \beta$ is the differential association of Council membership and news coverage between countries that are not allied at all, $A_{i}=0$, and countries that are "perfectly" allied, $A_{i}=1 . \alpha+\beta$ is the "net" or "total" association between news coverage and Council membership for countries that are perfectly allied with the United States. In the context of our conceptual framework, finding $\hat{\beta}<0$ will be consistent with the presence of government distortion (i.e., the news is partly determined by U.S. government distortion), and that $\hat{\alpha}>1$ will be consistent with the presence of reader demand effects (i.e., the news is partly determined by reader demand). These two effects are not mutually exclusive and can co-exist. Finding that $\hat{\alpha}+A \hat{\beta}<0$ means that for a country that is allied with the United States by $A$ or more, Council membership will reduce news coverage. 
Interpreting the association between the interaction effect and news coverage as causal requires the assumption that Council membership does not differentially affect allies in some way that will influence news coverage through channels other than U.S. government distortion or reader demand. Specifically, for the interaction term to overstate the true degree of government distortion, the omitted factor needs to reduce the increase in news coverage according to the level of political alliance with the United States. For example, if improvement in human rights practices when entering the Council is positively correlated with alliance, then the interpretation of our estimates will be confounded. We will carefully consider this and other robustness concerns after we present the main results.

\section{Data}

This paper uses data that are constructed from numerous publicly available sources. For brevity, we only describe the data for the main analysis in this section. Other data will be discussed as they become relevant.

News coverage of human rights violations is measured as the number of newspaper articles about human rights abuse in a given country. Following the definitions used by Freedom House and the Political Terror Scale project, we define human rights as physical violence committed by the state onto civilians. We calculate the number of articles based on a search of the text of articles in the ProQuest Historical and National Newspapers database. We search for articles containing the country's name, the phrase "human rights" and require at least one of the words or phrases that fall under the UN Declaration for Human Rights (and that are therefore also commonly used in news articles on human rights abuse). These include "torture", "violations", "abuse", "extrajudicial", "execution", "arbitrary arrests", "imprisonment" and "disappearances". Our measure of human rights coverage is the total number of articles that results from the search per country per year. The newspapers we examine are The New York Times (NYT), The Washington Post, The Wall Street Journal (WSJ, only available 1976-91), The Chicago Tribune (only available 1976-86) and The Los Angeles Times (L.A. Times). ${ }^{19}$ These are the only newspapers with high circulation for which we could conduct a full text search for the main period of our study. All of the newspapers in our

\footnotetext{
${ }^{19}$ In an earlier version of the paper, we also used news from the Christian Science Monitor. Since we want to focus in newspapers with large circulation, we have dropped this much smaller newspaper from the sample. All of the results are similar with its inclusion. Please see the earlier version for those results.
} 
sample are in the top ten of the highest circulation newspapers in the United States. Our measure includes both articles written by journalists employed by newspapers and stories picked up from newswires and other sources, although the newspapers in our sample, and in particular the NYT and Washington Post, were known for original international news reporting. ${ }^{20}$ This does not affect the interpretation of the results, but for completeness, we will also examine the impact on articles from newswires after we present the main results.

We proxy for the degree of alliance with the United States during the Cold War using the mean fraction of votes that a country votes in agreement with the United States on issues for which the United States votes in opposition to the Soviet Union in the UN General Assembly, $A_{i}$, where $A_{i} \in[0,1] .{ }^{21}$ Our measure of alliance includes abstentions. ${ }^{22}$ Our main measure of alliance is the fraction of votes a country voted with the United States averaged over the period 1985-88. This period provides us with the highest number of divided votes and therefore the best measure of alliance during this period. We use a time-invariant measure of alliance because it is less likely to be an outcome of changing U.S. favoritism than a time-varying measure and because using voting patterns from years where there were very few divided issues produces a very noisy measure of alliance. $^{23}$

Data on Council membership are collected from The United Nations Security Council Membership Roster. ${ }^{24}$ This is a time-varying dummy variable for whether a country is a rotating member

\footnotetext{
${ }^{20}$ The source of the story is often embedded within an article. Therefore, we were not able to accurately and systematically distinguish between articles written by different sources.

${ }^{21}$ Each year, there are approximately 100-150 resolutions in the Assembly, of which the United States and U.S.S.R. disagree on approximately 70-90. We do not examine voting patterns in the Council because most issues are discussed prior to being put onto the agenda. Therefore, the sample of issues voted on are not representative of the actual issues being deliberated by Council members.

${ }^{22}$ Excluding them does not significantly change either the measure of alliance or the regression results. For brevity, we do not report those results in the paper.

${ }^{23}$ Figure A.1 plots the fraction of divided votes over time. It shows that as Cold War tensions escalated in the 1980 s, the fraction of divided votes increased from approximately $30 \%$ during the late 1970 s to almost $70 \%$ in the late 1980s. Also plotted are the fraction of votes with the United States averaged over all the divided votes each year.

Using the measure of alliance presented in the paper, the top three allies of the United States and the fraction of divided issues they voted with the United States are: Turkey (0.4), Belize (0.28) and Costa Rica (0.27). The three countries that are least allied are Mongolia (0), Lao PDR (0), and Czech Republic (0). Our estimates are robust to changing the measure of alliance to be the average of votes during periods between 1981 and 1989, when there were many divided votes. The magnitude of the estimates vary slightly across different definitions, but the results are always qualitatively similar. For brevity, we do not report estimates with these alternative measures in the paper. They are available upon request.

${ }^{24}$ See http://www.un.org/sc/list_eng5.asp for a list of all countries that were ever members and the years of their memberships. 46 countries in the sample were on the Council as a rotating member at least once during this time. They are listed in Appendix Table A.1. 21 countries were on the Council at least twice, among which five countries were on the Council three times.
} 
of the UN Security Council, $C_{i t}$.

We will also use reports on human rights practices in our analysis. These indices are provided by the Political Terror Scale (PTS) project for the years 1976-2005 and measure the annual extent of human rights violations according to two sources: the U.S. Department of State (USSD) Country Reports on Human Rights Practices, and the Amnesty International Annual Report. The PTS uses a five point coding scheme, where a PTS value of five indicates the most severe abuse, and a PTS value of one means that the country is under a secure rule of law and people are not imprisoned for their views. The scale is based on an earlier one developed by Freedom House. As we are interested in countries that commit human rights violations, we restrict our analysis to countries that have an Amnesty International PTS value above one in at least one year. ${ }^{25}$

The final sample of countries excludes former Soviet Republics that did not have membership in the United Nations before 1991 and South Africa, which was excluded from UN activities due to the UN's opposition to apartheid. The five permanent members of the Council are also excluded since they cannot experience any variation in Council membership.

The main analysis focuses on the Cold War years, 1976-88. The sample begins in 1976 because of the limitation of the PTS data. The sample ends in 1988, the year prior to the fall of the Berlin Wall, which we interpret as the "beginning of the end" of the Cold War era. Our estimates are qualitatively similar if we include $1989-1991 .^{26}$ The main sample comprises of an unbalanced panel of 91 countries. The panel is unbalanced due to the fact that the number of countries in the United Nations increases over time. After we present the main results, we will show that our estimates are not driven by selection of countries into the United Nations, and we will also show the results from using data from the post-Cold War period.

Table 1 presents the descriptive statistics. Panel A shows the Cold War period. Panel B shows the post-Cold War period. We focus our discussion on the former. The data show that the average country in our sample votes with the United States on $8.9 \%$ of divided issues. Approximately $7 \%$ of the country-year observations are Security Council members. The sample average for human rights

\footnotetext{
${ }^{25} \mathrm{~A}$ PTS value of two implies (among other things) there is "a limited amount of imprisonment for nonviolent political activity... A few persons are affected; torture and beating are exceptional... and political murder is rare." The CIRI Human Rights Data Project, like the PTS Project, reads the reports by Amnesty and the State Department and provides a score. However, the CIRI indices only begin in 1981. They also differ from PTS in that they attempt to provide disaggregated indices for the type of human rights. This means that while the two indices are correlated (approximately 0.65-0.73), they are not directly comparable. See Wood and Gibney (2010) for a detailed discussion.

${ }^{26}$ These results are available upon request.
} 
practices is "medium" since the PTS index ranges from one to five and the mean PTS in the sample is close to three. The U.S. State Department reports countries as having better human rights, on average, than does Amnesty International.

The statistics also show that approximately $60 \%$ of the country-year observations have at least one news article published on human rights in a U.S. newspaper. The U.S. newspapers in our sample published almost eight articles about the human rights abuses of the average foreign country in our sample each year. The Washington Post, New York Times and Los Angeles Times published three to ten times as many articles as the Wall Street Journal or the Chicago Tribune. We will discuss newswire and U.K. newspapers later in the paper.

\section{Results}

\subsection{Main Results}

In this section, we present the estimates of equation (6). Table 2 presents our main results on news coverage. The sample means of the dependent variables are presented at the top of the table. Our main measure of news coverage is the log of the number of news articles about country $i$ 's human rights abuses during year $t$ across all newspapers. ${ }^{27}$ In panel A column (1), we control for the uninteracted U.S. alliance term instead of country fixed effects to examine the coefficient for this variable. When we do this, the interaction effect is negative, but statistically insignificant. The main effect of Council membership is positive, but statistically insignificant. The main effect of alliance is positive and almost significant at the $10 \%$ level, which implies that alliance and news coverage is positively correlated for countries not on the Council. However, this should be interpreted very cautiously as only suggestive because U.S. alliance is almost certainly endogenous to a large number of other factors. ${ }^{28}$

Column (2) replaces the control for U.S. alliance with year fixed effects. This greatly increases the precision of the estimates for the interaction effect and the uninteracted Council effect without causing much change to the magnitudes of the estimates. The interaction effect is statistically significant at the $10 \%$ level and the uninteracted Council effect is significant at the $1 \%$ level. In

\footnotetext{
${ }^{27}$ If there are zero articles, we calculate this as the $\log$ of 0.1 to maximize sample size. To check that our results do not rely on this transformation, we will later show the estimates for the number of articles (without taking logs) and the log number of articles on a sample restricted to observations where there is at least one article.

${ }^{28}$ Note that our model, which assumes that readers do not distinguish allies from non-allies, is silent on the relationship between alliance and news coverage for non-Council members.
} 
column (3), we replace the control for the uninteracted Council effect with the interaction of the Council dummy with the full vector of year fixed effects to address the possibility that the importance of Council members to the U.S. government or the prominence of the Council to the American public changes over time. Adding this control increase the precision of the interaction effect to the $1 \%$ significance level.

In column (4), we additionally control for the interaction of U.S. alliance and the full vector of year fixed effects to address the possibility that the relationship between the U.S. government and its allies changed over time. Note that by interacting Council membership and U.S. alliance with year fixed effects, we are allowing the influences of each to be fully flexible over time. Thus, our main interaction effect is only driven by variation in news coverage that systematically varies with alliance and Council membership that is not captured by this rigorous set of controls. Column (4) is our baseline specification.

Interpreted within our framework, the positive estimates of the Council main effect in columns (1)-(2) show that reader demand effects are present in our context. The negative interaction effects in columns (1)-(4) show that government distortion is also present. To assess the magnitude of the estimated distortion implied by the coefficients in column (4), we compare the effect of Council membership for a country that is on the 75 th percentile of the distribution of U.S. alliance that votes with the United States on approximately 10.6\% of divided issues on average (e.g., Ecuador, Egypt) to a country that is on the 25th percentile of the distribution of alliance that votes with the United States on approximately $4.3 \%$ of divided issues on average (e.g., Mali, the Republic of Congo). This is shown at the bottom of the table. We find that Council membership of the stronger ally will result in $42 \%(-6.62 \times(0.106-0.043)=0.42)$ less coverage relative to membership of the weaker ally.

Another way to assess the magnitude of the estimates is to ask how strong alliance needs to be for Council membership to reduce news coverage, and how many countries in the sample were sufficiently allied to experience this reduction. For this back-of-the envelope calculation, we use the estimates in column (2), which show that the uninteracted coefficient for Council membership is 0.43 and the interaction coefficient is -5.04 . This implies that a country that votes with the United States on $8.5 \%$ or more of divided issues will experience a reduction in news coverage when entering the Council $(5.04 / 0.43=0.085)$, which applies to $39 \%$ of the countries in our sample. 


\subsection{Sensitivity}

\subsubsection{Alternative Measures of News Coverage and Sample Restrictions}

In column (5), we examine the number of news articles (without logs) as the dependent variable. The estimates are similar in sign and statistically significant at the $10 \%$ level. The differential effect on the 75th percentile and 25th percentile allies shown at the bottom of the table imply that Council membership will result in approximately eight fewer stories for the stronger ally relative to the weaker one.

In Column (6), we examine a dummy variable that equals one if there is at least one news article about country $i$ 's human rights abuses in year $t$ (in any newspaper). This reveals whether the main results are driven by changes in news coverage for countries that are typically not covered by U.S. newspapers (i.e., the extensive margin), or changes in the number of stories for countries that already receive some coverage (i.e., the intensive margin). The estimate is similar in sign, but is not statistically significant at conventional levels.

In column (7), we return to examining the main outcome variable, the log of the number of all news articles, but restrict the sample to country-year observations that have at least one article. The estimated interaction effect is nearly identical to our main estimates in magnitude, sign and precision. In column (8), we restrict the sample to countries that are covered at least once during the sample period. Again, the estimates are nearly identical to the baseline. The estimates in columns (5)-(8) show that our estimates are more precisely estimated for countries that typically receive some news coverage of human rights abuses, which may simply reflect the fact that these are the countries with governments that commit human rights abuses.

In column (9), we check that our estimates are not solely driven by the countries with the worst

or best human rights practices by dropping the five percent of countries that have the worst practices and the five percent with the best practices. Specifically, we drop countries with highest or lowest 5\% average (over the sample period) PTS scores according to either the U.S. State Department or Amnesty PTS scores. The estimates in column (9) show that our main results are very robust to excluding the countries with the best and worst human rights behavior from the sample.

In column (10), we restrict the sample to the years of the Reagan Administration (1980-1988), from which most of the case evidence we presented earlier are from. As expected, the estimates are 
very similar to the main results.

In column (11), we restrict our sample to countries that were on the UNSC at least once during our sample period. The estimates are similar to the baseline, which shows that the baseline estimates are not driven by countries that were never on the Council.

In column (12), we estimate an alternative specification to examine whether the relationship between alliance and UNSC membership is monotone across alliance levels. For this exercise, we divide countries into five equally sized groups according to how closely they are allied to the United States. We then interact each of the five alliance dummy variables with UNSC membership. Since we include all five interactions, we exclude the UNSC membership main effect, which is collinear. We exclude the interactions of UNSC and year fixed effects and U.S. alliance and year fixed effects. The estimates show that the coefficients are indeed monotonically declining with alliance. The pattern across coefficients is consistent with our model. The interaction terms for the weakest and strongest alliance groups are significant at the $1 \%$ level.

\subsubsection{Timing of the Effect}

Interpreting the association between the interaction of UNSC membership and U.S. alliance and news coverage as a causal relationship assumes that conditional on the baseline controls, there are no other factors that are simultaneously correlated with UNSC membership and the degree of political alliance with the United States (i.e., omitted variables) that can also affect news coverage. Specifically, for the interaction term to overstate the true degree of government distortion, the omitted factor needs to reduce the increase in news coverage from Council membership according to the level of political alliance with the United States. For very strongly allied countries, this omitted factor needs to cause Council membership to result in less coverage. In the remaining robustness section, we provide evidence that our estimates are unlikely to be driven by such omitted variables in two exercises.

First, we show that the main results are unlikely to be driven by spurious correlations. The most direct way to do so is to estimate the effect for each year prior to and after a country is on the UNSC. To investigate this, we estimate an equation similar to our baseline, except that instead of a dummy variable indicating Council membership, we create seven dummy variables for two years before Council membership is announced, one year before it is announced, the year it is announced, the first year of Council membership, the second year of Council membership, one year afterwards 
and two years afterwards. ${ }^{29}$ We control for these seven dummy variables and their interactions with U.S. alliance, in addition to the baseline controls of the interaction of U.S. alliance with year fixed effects, the interaction of Council membership with year fixed effects, and country and year fixed effects.

For comparison purposes, we conduct this analysis for both the Cold War and post-Cold War sample. Given that our empirical strategy applies to the Cold War, finding that the coefficients are similar in the years leading up to and after Council membership, but diverge during Council years between the Cold War and post-Cold War samples would lend credibility to our interpretation that our main results indeed capture changes that occur that depend on Cold War alliance when a country is on the Council. Since Council memberships are announced one year in advance and the announcement often results in news coverage of the country that includes discussion about its human rights practices, the effects could begin the year before Council membership. ${ }^{30}$

The coefficients and standard errors of the interaction variables for the Cold War and post-Cold War periods are presented in Appendix Table A.2, and are plotted on Figure 2a. ${ }^{31}$ The figure shows that the interaction terms for the years leading up to and after Council membership are similar during the two time periods, but diverge the year before a country's entry onto the Council once its election is announced, is most pronounced for the first year of Council membership, and converges after exiting the Council. During the Cold War, the interaction terms during Council membership are negative, while they are zero during the post-Cold War period. These results are consistent with the previous results that our estimates are particular to the Cold War era. The divergence that occurs close before entry onto and after exit from the Council also means that our main results are unlikely to be driven by spurious trends.

Figure 2b plots the year-by-year interaction coefficients for each news paper. For brevity, we only plot the interaction coefficients for the Cold War era. The timing of the effect is broadly similar

\footnotetext{
${ }^{29}$ Since our Cold War sample only include thirteen years, the number of observations are obviously not balanced across the pre and post years (i.e., the number observations declines as we examine more years before and after membership). However, the patterns exhibited by our results are very similar regardless of the number of preand post-Council years we examine. Hence, we present the estimates with many pre and post years for illustrative purposes. Alternative results are available upon request.

${ }^{30}$ Note that in the main analysis, the Council membership dummy variable takes a value of zero for the year of the election. Thus, if the announcement results in news coverage of human rights abuses, our main results will be attenuated.

${ }^{31}$ The coefficients of the interaction terms and their $95 \%$ confidence intervals for the Cold War period are plotted in Appendix Figure A.4a.
} 
across papers. Thus, the timing of the effect on all articles is not driven by any one newspaper.

Note that the finding that there is no effect in the post-Cold War era has several potential interpretations. It could simply be the case that our measure of alliance is no longer relevant after the Cold War ended. Alternatively, the U.S. government may value human rights more after the Cold War period and be unwilling to ally itself with governments that have bad human rights practices. Both interpretations are consistent with the main of the paper that Cold War news coverage was influenced by the U.S. government. They are also consistent with the anecdotal evidence. For example, the president of Zaire (renamed the Democratic Republic of Congo in 1997), Mobutu Sese Seko (in office 1965-1997) was a strong supporter of the United States during the Cold War and had been repeatedly criticized for human rights abuses. However, during a state visit to the United States in 1983, United States president Ronald Reagan responded to these criticism by stating publicly that Mobutu was a "voice of good sense and good will". Immediately after the Cold War ended, the State Department began to criticize Zaire's human rights violations. In 1993 Mobutu was denied a visa for visiting the United States and said "I am the latest victim of the Cold War, no longer needed by the United States. The lesson is that my support for American policy [now] counts for nothing" (Gbadolite, 2011).

\subsubsection{Additional Controls}

Second, we address the concern of simultaneity bias by controlling for the factors that are most likely to influence news coverage and be correlated with Council membership. Table 3 column (1) restates our baseline for comparison purposes. Column (2) controls for region-year fixed effects to address the possibility that reader interests and U.S. policy objectives may shift geographically over time. We use the Hadenius and Teorell (2005) definition, which divides the world into ten regions according to geo-political characteristics. Column (3) controls for political characteristics of foreign countries that may influence U.S. readers' interests in these countries, the strategic value of their alliance to the United States and a country's ability to obtain Council membership. We use the Freedom House indices of Civil Liberty and Political Rights and the Polity2 index for constraints on the executive. ${ }^{32}$ For each variable, we calculate the average for each country over our sample period. This maximizes the sample size and lessens the concern that contemporaneous measures

\footnotetext{
${ }^{32}$ The Freedom House indices range from 1 (most free) to 7 (least free). Polity2 is an index that measures the autocracy of the executive. It ranges from -10 to 10 , where higher values reflect more democratic governments and is reported by the Polity IV Project. These variables are all reported by the Quality of Governance (QoG) data.
} 
can be outcomes of Council membership and alliance. To allow the influences of these variables to vary over time, we control for the interactions of each variable with the full vector of year fixed effects. In column (4), we control for average human rights abuse levels interacted with the full set of year fixed effects. In column (5), we control for average real GDP (as reported by the Penn World Table) interacted with year fixed effects to address the possibility that a country's wealth is correlated with its alliance to the United States, Council membership and news coverage. In column (6), we control for all of the additional variables in one regression. The interaction effect is always negative, large in magnitude and statistically significant at the $1 \%$ level.

In column (7), we address the possibility of spurious trends by controlling for country-specific linear time trends. The estimated interaction effect is nearly identical to the baseline result and significant at the $1 \%$ level.

In column (8), we control for three lags of the dependent variable to address the possibility that there may be some mechanical persistence in coverage over time. For example, if there is a fixed cost to reporting news of a foreign country (e.g., setting up a foreign office or hiring reporters that speak a foreign language), then "setting up shop" to report on events in a foreign country in a given year will reduce the average cost of reporting the following years and can thereby lead to more coverage the following years. The estimates are very robust to these controls, but should be interpreted only as suggestive since controlling for lagged dependent variables can introduce the Nickel (1981) bias.

The robustness of our results to additional controls, together with the finding that the timing of the reduced form effects correspond to the timing of Council election and exit, imply that the main findings are unlikely to be driven by omitted variables.

\subsubsection{Additional Sensitivity Checks}

Here, we check that our estimates are not driven by the selection of countries into the United Nations over time. The main sample includes 103 countries over a period of thirteen years (197688). 93 countries are observed for at least 5 years of the sample. 66 countries are observed for ten or more years. 25 countries are observed for all thirteen years. Columns (9)-(11) show that the coefficients are similar in magnitudes and in signs when we restrict the sample to countries that are observed for five or more years, ten or more years, or all thirteen years. The coefficients are always negative, large in magnitude and statistically significant at the $1 \%$ level. Thus, the main results are not driven by selection into the United Nations over time. 
In addition to the exercises presented in the paper, we also checked that our main estimates are not driven by outliers or particularly influential variables. We calculate the DF betas of each observation to examine how influential each observation is to our regression estimate, and then find that our estimates are very similar when we drop the top five, ten, etc. influential observations. These estimates are available upon request.

\subsection{Mechanisms}

The main results are consistent with the conceptual framework presented in section 3 that news coverage is influenced by government distortion, as well as by reader demand. In this section, we provide additional evidence consistent with the presence of government distortion, as well as evidence that contradicts the main alternative explanation.

\subsubsection{U.S. State Department Reports}

Since our preferred explanation for the negative interaction effect in the main analysis is that the degree of government suppression of news coverage of human rights abuses increases with alliance, we examine whether reports of human rights abuses made by the U.S. government decrease with alliance when a foreign country enters the Council. While it is beyond the scope of our analysis to quantitatively determine the contribution of the different policy instruments used by the U.S. government to distort the news (recall the discussion in Section 2), finding that official government reports respond to U.S. alliance and Council membership in a similar way would provide evidence that our empirical strategy does indeed capture U.S. government objectives.

We examine the U.S. State Department's Country Reports on the level of human rights practices of each country. This is an annual publication submitted to Congress and open to the public, including journalists. ${ }^{33}$ That journalists are aware of this publication is consistent with the spike in the number articles about human rights printed in newspapers the day after the reports are announced. ${ }^{34}$ As the content is entirely determined by the government, it is one of many instruments

\footnotetext{
${ }^{33}$ The United States is the only country that systematically releases its reports to the public. The way in which it gathers information is not transparent. However, it is generally assumed that the reports are based on information from government intelligence and diplomatic apparatuses. The wording of the reports also suggest that the information is mostly based on these sources.

${ }^{34}$ Appendix Figure A.2 plots the average number of articles over time for each day before and after the Country Reports are released. The release dates vary year to year. There is a spike in the number of articles the day following the release. However, the total number written in the days following the release of the reports are less than one-tenth of all of the articles written during an average years. This is consistent with the belief that although Country Reports can serve as a reference for journalists writing about human rights, their release does not determine the timing of most news articles about human rights.
} 
by which the government can influence the media. Our hypothesis implies that Country Reports should favor UNSC members that are allies relative to those that are less allied to the United States. Finding this relationship in the data would lend additional credibility to the interpretation of our empirical results.

A potential concern from examining State Department reports of human rights practices is that the reports will capture both government distortion and actual human rights practices. Thus, observing that these reports vary with alliance and Council membership could mean that either the U.S. government distorts reports for strong allies on the Council or that strong allies on the Council improve human rights practices more than less allied countries. To address this, we benchmark the State Department country reports to those by Amnesty International. Since Amnesty is a nongovernment organization, it should not systematically bias its reports based on U.S. government objectives. As we discussed in the section on Data, both reports are quantified by the Political Terror Scale (PTS), where lower scores reflect better practices.

In Table 4, we first examine each PTS score separately. Columns (1) and (2) show that the signs of the interaction term, the uninteracted Council term and the uninteracted U.S. alliance term are different for the State Department and Amnesty PTS scores. However, none are statistically significant. In column (3), we examine the difference between the State Department and Amnesty PTS scores as the dependent variable. The signs are consistent with those shown in columns (1) and (2), but the estimates are much more precise. The negative sign for U.S. alliance implies that relative to Amnesty, the State Department reports allies that are not on the Council as having better human rights practices. The positive sign on the uninteracted Council membership term implies that relative to Amnesty, the State Department reports a country that never votes with the U.S. as having worse human rights practices. The negative interaction term implies that the stronger the alliance, the more the State Department will favor it with reports of good human rights practices (relative to Amnesty) when a country enters the Council.

In column (4), we introduce the baseline controls. The interaction effect is still positive and statistically significant at the $1 \%$ level. In column (5), we exclude countries with the top or bottom 5\% PTS scores according to either Amnesty or the State Department. In column (6), we restrict the sample to the Reagan era. In column (7), we restrict the sample to countries that were on the Council at least once during our sample period. The estimates are very robust. 
In column (8), we divide the countries into five equally sized groups of alliance and interact a dummy indicating that a country is in each group with the Council membership dummy. These estimates are imprecise, but the coefficients suggest a pattern that is consistent with our interpretation. The coefficient is more negative for more allied countries. For the most strongly allied group, the coefficient is statistically significant at the $1 \%$ level. As with the analogous results on news coverage, these estimates suggest that the degree of U.S. government distortion of a foreign country's human rights abuses is roughly monotonically increasing in alliance.

As with the main results on news coverage, we can examine whether the timing of the reduced form results for the difference in U.S. State Department and Amnesty PTS scores correspond to entry and exit from the Council. We estimate a similar equation as before, where we control for the seven dummy variables for the years since Council membership and their interactions with U.S. alliance. Figure 3a plots the interacted coefficients for the years since Council membership dummy variables for the Cold War and post-Cold War sample. ${ }^{35}$ As with news coverage, the effects are similar between the Cold War and post-Cold War periods for the years prior to and after Council membership, while for the years on the Council, the coefficients diverge. Moreover, when we examine State Department and Amnesty PTS during the Cold War separately, Figure 3b shows that the two scores are similar for the years prior and after Council membership but divergent for the years on the Council.

The results in this section support the interpretation of our main results.

\subsubsection{Alternative Explanation}

The main alternative explanation for our results is the possibility that strongly allied countries improve actual human rights practices (relative to weaker allies) when they enter the Council. This seems unlikely given that Table 4 shows that there is no effect on human rights practices as reported by Amnesty International. However, to investigate this possibility more thoroughly, we also examine institutional outcomes that are potential correlates of human rights practices. We use all of the measures that are available to researchers today and that are reported by non-government agencies. These include the Civil Liberties and Political Rights indices reported by Freedom House, the Polity 2 Index for constraints on the executive and the incidence of civil conflict that results in 25 or more battle deaths as reported by UCDP/PRIO. For Polity2, we follow the literature and use a dummy

\footnotetext{
${ }^{35}$ The estimates and their $95 \%$ confidence intervals for the Cold War period are shown in Appendix Figures A.4b.
} 
that equals one if the index is less than zero to indicate that a country is an autocracy. ${ }^{36}$

Table 5 begins with the Amnesty PTS score. ${ }^{37}$ Columns (3)-(10) show the estimates for the other outcomes. For each outcome, we show both a specification that shows the uninteracted Council effect as well as the baseline specification that controls for the interaction of year fixed effects with the Council dummy and with U.S. alliance. The interaction effect is statistically insignificant for all outcomes. To help compare the magnitudes of the effects across the outcomes, we standardize the estimates. At the bottom of the table, we present the standard deviation change in the dependent variable that results from a one standard deviation change in the interaction term. The standardized effects are similarly small in magnitude across outcome variables. In terms of absolute value, the standardized effect for the baseline estimates in the evenly numbered columns range from 0.01 to 0.025. In contrast, a one standard deviation change in the interaction term causes a much larger - a 0.1 standard deviation - change in the log of news articles on human rights abuses (this is not shown in the tables).

In the last column, we examine the first principal component of all of the institutional measures. As before, we find no effect. These estimates are inconsistent with the alternative interpretation that our estimates are driven by improvements in the relative human rights practices of strongly allied countries when they enter the Council.

\section{Additional Results}

This section provides speculative results that can potentially help to extend our understanding on the determinants of news coverage.

\subsection{Distortion, Newspaper Quality and Circulation}

A natural question that follows from the main analysis, which focuses on the total number of news articles across papers, is whether the degree of distortion in each newspaper is correlated with the quality of foreign news reporting or a newspaper's reputation. For example, Besley and Prat (2006) argues that in the presence of government manipulation, the government will focus its efforts on newspapers with good reputations. This may be because distorting the coverage of high quality

\footnotetext{
${ }^{36}$ These variables are provided by the Quality of Government (QoG) dataset. In addition to what is presented here, we examine a large array of other variables reported by the QoG dataset and find no effect on any of them. These results are available upon request.

${ }^{37}$ The estimates are slightly different from Table 4 column (2) because the specification is different.
} 
newspapers will have a larger impact on reader perceptions because readers place more trust in high quality newspapers. In the context of our study and model, it can also be because readers who are interested in foreign news may be more likely to read newspapers with a good reputation for foreign news coverage. ${ }^{38}$

To explore this, we examine the correlations of the estimated coefficients across for each newspaper with a proxy for the quality of foreign journalism: the number of Pulitzer Prizes in International Reporting for each newspaper during 1976-2005. ${ }^{39}$ Table 6 columns (1)-(10) present the estimated effects on the New York Times, Washington Post, Wall Street Journal, The Chicago Tribune and The L.A. Times. For each paper, we show both the specification with the uninteracted Council effect as well as the baseline specification. We will focus our discussion on the interaction term in the baseline specification shown in the even numbered columns. The estimated interaction effect is negative for all papers, but varies in magnitude and precision. ${ }^{40}$

Next, we use a bivariate regression to estimate the correlations between the estimated effects for each paper and the quality measure. Figure 4 a plots the respective regression line and data points. Consistent with our framework, it shows that the degree of distortion (the absolute value of the interaction coefficient) is larger for newspapers with more Pulitzers.

\subsection{Distortion and Reader Preferences}

Given that news is determined both by reader demand and government distortion, another question that arises from our results is whether the degree of distortion is aligned with reader preferences across papers. For example, it may be easier for a strongly anti-communist government to distort newspapers with more conservative readers. To explore this, we examine the correlations of the estimated coefficients with a ranking of reader attitude according to the 2008 Mondo Conservativeness Rating. ${ }^{41}$

As before, we use a bivariate regression to estimate the correlations between the estimated effects

\footnotetext{
${ }^{38}$ It is straightforward to extend the framework presented in Section 3 to incorporate newspaper quality effects. This is available upon request.

${ }^{39}$ The data are shown in Appendix Table A.3. The number of Pulitzer Prizes are from http://www.pulitzer.org/bycat/International-Reporting. Our results are similar if we use the number of prizes from larger or smaller windows of time. Similarly, the qualitative point is unchanged if we use prizes from all categories. These results are available upon request.

${ }^{40}$ Note that there are fewer observations for the Chicago Tribune because it is not available for text analysis for all years in the sample. Our main results examining all articles are similar if we omit the Tribune from our sample. Thus, they are not driven by the selection of newspapers into the ProQuest database.

${ }^{41}$ The data are shown in Appendix Table A.3.
} 
for each paper shown in Table 6 and the conservativeness ranking. Figure $4 \mathrm{~b}$ plots the respective regression lines and data points. It suggests that government distortion was larger in magnitude is less conservative newspapers. ${ }^{42}$ This is consistent with the model in that the U.S. government will attempt to distort news where it can affect the opinions of the highest number of U.S. voters, if readers of conservative newspapers are more likely to support the incumbent government despite the human rights abuses of its allies (e.g., conservatives may value the objectives of the Reagan era policy more than other voters).

Note that the estimates of the correlations across papers should be interpreted loosely as merely suggestive for several reasons. First, we observe very few newspapers. Second, the bivariate correlations do not take into account the fact that the degrees of distortion are estimates. For these two reasons, we do not present the standard errors of the bivariate correlations. Finally, the Mondo conservativeness measure is from many years after the period of our study and may not accurately represent the views of readers during the Cold War.

\subsection{Newswires and U.K. Newspapers}

Since a significant amount of foreign news in newspapers is originally reported by newswires such as the Associated Press, we examine the effect on newswires in Table 6 columns (11)-(12). The estimates for both the interacted and uninteracted terms are similar to our baseline estimate in sign; they are large in magnitude and statistically significant at the $1 \%$ level.

In order to use all of the available data, we also collect data on the number of news stories about human rights abuses published in a United Kingdom newspaper, The Guardian. Columns (13)-(14) show that there is no effect on coverage in this U.K. newspaper. While there are many potential explanations for the difference in coverage between U.S. and U.K. newspapers, these results are consistent with the two mechanisms highlighted in our model, since the British government has plausibly less leverage over U.S. newspapers and U.K. readers are likely to have different interests from American readers.

\footnotetext{
${ }^{42}$ We also find that the degree of distortion is uncorrelated with the slant measure from Gentzkow and Shapiro (2006). These are not presented for brevity and available upon request.
} 


\section{Conclusion}

This paper explores the possibility that the government can systematically distort news coverage from independently owned media outlets in the United States. Using data from the latter part of the Cold War, we find that membership on the Security Council increased news coverage of the human rights abuses of foreign countries when they are not politically allied to the United States. In contrast, for countries that are strongly allied to the United States, membership reduced news coverage of bad behavior. We argue that these results are consistent with news coverage being driven by two forces: government distortion and reader interests. The government distortions that we detect in the data dissipate with the end of the Cold War. This could be due to the inability of the U.S. government to sustain manipulation, or to a shift in political alliances after the Cold War that causes our measure of Cold War alliance to no longer be meaningful.

These results provide novel and rigorous evidence that government distortion can systematically exist (albeit for a finite period of time) in a highly competitive media market amongst independently owned media. For policymakers and practitioners, our results produce mixed forebodings. On the one hand, they confirm anecdotal evidence that there is systematic government distortion in U.S. media content and are consistent with the fear that government distortion can impede the media's ability to monitor the government on behalf of its readers. On the other hand, the fact that our results dissipate after the Cold War suggests that perhaps government distortion would not have been sustainable over time. It is beyond the scope of our study to be conclusive on this point.

The results and limitations of our study suggest several avenues for future research. We need to determine whether systematic government distortion of independently owned media in democracies has existed outside of our context. Another closely related subject of research is to understand the conditions under which a democratically elected government can systematically distort the news. Our finding that there is distortion during the Cold War together with the recent work of Gentzkow, Petek, Shapiro, and Sinkinson (2012), which finds that the government in power has little effect on news composition in the historical U.S. context, suggests that there is variation in government distortion even within one political regime. Better understanding of the determinants of a democratically elected government's ability to distort the news is an important avenue of future research. 
Caution is needed for extrapolating our estimates to other countries or time periods. The estimates we obtain are specific to the context of our study. Nevertheless, it is important to note that the United States has one of the largest and most competitive media markets in the world (Djankov and Shleifer, 2003). Given the argument that government distortion decreases with market competition and independent ownership, the degree of government distortion in the United States can potentially be interpreted as the lower bound of the extent of government distortion in other democratic regimes. 


\section{References}

Alesina, A., And D. Dollar (2000): "Who Gives Foreign Aid to Whom and Why?," Journal of Economic Growth, 5(1), pp. 33-63.

Bennet, Lance, L. R., and S. Livingston (2007): When the Press Fails: Political Power and the News Media from Iraq to Katrina. University of Chicago Press, Chicago.

Bennett, W., R. Lawrence, and S. Livingston (2008): When the Press Fails: Political Power and the News Media from Iraq to Katrina, Studies in Communication, Media, and Pub. University of Chicago Press.

Berger, D., W. Easterly, N. Nunn, and S. Satyanath (2012): "Commercial Imperialism? Political Influence and Trade During the Cold War," The American Economic Review.

Berger, D., W. Easterly, and S. Satyanath (2009): "Was Lenin Right? US Political Influence and International Trade during the Cold War Era," Discussion paper, Harvard University Working Paper.

Besley, T., And A. Prat (2006): "Handcuffs for the Grabbing Hand? Media Capture and Government Accountability," The American Economic Review, 96(3), pp. 720-736.

Blanton, S. L., and R. G. Blanton (2007): "What Attracts Foreign Investors? An Examination of Human Rights and Foreign Direct Investment," The Journal of Politics, 69(1), pp. 143-155.

Brooks, J. (1987): "Letter to The Honorable Dante B. Fascell (on the Investigation of the Office of Public Diplomacy)," Discussion paper.

Carleton, D., and M. Stohl (1985): "Foreign Policy of Human Rights: Rhetoric and Reality from Jimmy Carter to Ronald Reagan," Human Rights Quarterly, 7(2), pp. 205-229.

Chinang, C.-F., and B. Knight (2011): "Media Bias and Influence: Evidence from Newspaper Endorsements," Review of Economic Studies, 78(3), 795-820.

Cohen, J. (2001): "The Return of Otto Reich: Will government propagandist join Bush Administration?," Discussion paper, Fairness and Accuracy in Reporting.

Cook, T. (1998): Governing with the News: The News Media as a Political Institution, Studies in Communication, Media, and Pub. University of Chicago Press.

Della Vigna, S., and E. Kaplan (2007): "The Fox News Effect: Media Bias and Voting," Quarterly Journal of Economics, 122(3), pp. 1187-1234.

Djankov, Simeon, M. C. N. T., and A. Shleifer (2003): "Who Owns the Media?," Journal of Law and Economics, 46(2), pp. 341-81.

Dube, A., E. Kaplan, and S. NAidu (2011): "Coups, Corporations, and Classified Information," The Quarterly Journal of Economics, 126(3), pp. 1375-1409.

Durante, R., and B. Knight (2012): "Partisan Control, Media Bias, And Viewer Responses: Evidence From Berlusconi'S Italy," Journal of the European Economic Association, 10(3), 451481.

Enikolopov, Ruben, P. M., and E. Zhuravskaya (2011): "Media and political persuasion: Evidence from Russia," The American Economic Review, 101(7), pp. 3253-3285.

Gbadolite, A. Z. (2001): "Leaving Fire in His Wake," TIME Magazine.

Gentzkow, M. (2006): "Television and Voter Turnout," The Quarterly Journal of Economics, 121(3), pp. 931-972. 
Gentzkow, M., N. Petek, J. M. Shapiro, and M. Sinkinson (2012): "Do Newspapers Serve the State? Incumbent Party Influence on the US Press, 1869-1928," NBER Working Papers 18164, National Bureau of Economic Research, Inc.

Gentzkow, M., and J. M. Shapiro (2006): "What Drives Media Slant? Evidence from US Daily Newspapers," Discussion paper, National Bureau of Economic Research Working Paper No. 12707.

(2008): "Preschool Television Viewing and Adolescent Test Scores: Historical Evidence from the Coleman study," The Quarterly Journal of Economics, 123(1), pp. 279-323.

Gerber, A., D. Karlan, and D. Bergan (2009): "Does the Media Matter? A Field Experiment Measuring the Effect of Newspapers on Voting Behavior and Political Opinions," American Economic Journal: Applied Economics, 1(2), pp. 35-52.

Graber, D. A. (2006): Mass media and American politics, Mass Media and American Politics. CQ Press.

Hadenius, A., And J. Teorell (2005): "Cultural and Economic Prerequisites of Democracy: Reassessing Recent Evidence.," Studies in Comparative International Development, 39(4), 87106.

Hamilton, L. H., and D. K. Inouye (????): "Report of the Congressional Committees Investigating the Iran-Contra Affair with Supplemental, Minority, and Additional Views, 100th Congress, 1st Session," Discussion paper.

Jacobwitz, J. (1985a): "Duties of TDY Military Personnel (Memo to Ambassador Reich)," Discussion paper, National Security Archives.

(1985b): "Public Diplomacy Action Plan. Support for the White House Educational Campaign," Discussion paper, National Security Archives.

Jensen, R., And E. Oster (2009): "The Power of TV: Cable Television and Women's Status in India," The Quarterly Journal of Economics, 124(3), pp. 1057-1094.

Kuziemko, I., And E. D. Werker (2006): "How Much Is a Seat on the Security Council Worth? Foreign Aid and Bribery at the United Nations," Journal of Political Economy, 114(5), pp. 905930.

La Ferrara, E., A. Chong, and S. Duryea (????): "Soap Operas and Fertility: Evidence from Brazil," Discussion paper, Working Paper, Department of Economics, University of Bocconi, Milan, Italy.

Malone, D. M. (2000): "Eyes on the Prize: The Quest for Nonpermanent Seats on the UN Security Council," Global Governance, 6(1), pp. 3-23.

(2004): The UN Security Council: From the Cold War to the 21st Century, A project of the International Peace Academy. Lynne Rienner.

Miller, J. (2001): "White Propaganda, An Operation (Memo to Mr. Pat Buchanan)," Discussion paper, National Security Archives.

Mitchell, N. J., AND J. M. MCCormick (1988): "Economic and Political Explanations of Human Rights Violations," World Politics, 40(4), 476-498.

Olken, B. A. (2009): "Do television and radio destroy social capital? Evidence from Indonesian villages," American Economic Journal: Applied Economics, 1(4), 1-33.

O'Neill, B. (1996): "Power and Satisfaction in the United Nations Security Council," The Journal of Conflict Resolution, 40(2), pp. 219-237. 
PALUCK, E. L. (2009): "Reducing intergroup prejudice and conflict using the media: a field experiment in Rwanda," Journal of Personality and Social Psychology, 96(3), pp. 574-587.

Parry, R., and P. Kornblub (1988): "Iran-Contra's Untold Story," Foreign Policy, (72), pp. 3-30.

Poe, Steven C., C. S. C., and T. C. Vazquez (2001): "How Are These Pictures Different? A Quantitative Comparison of the US State Department and Amnesty International Human Rights Reports, 1976-1995," Human Rights Quarterly, 23(3), pp. 650-677.

Prat, A., And D. Stromberg (2005): "Commercial television and voter information," Discussion paper, CEPR Discussion Paper No. 4989.

(2011): "The Political Economy of Mass Media," Discussion paper, Mimeo, LSE and IIES.

Qian, N., And D. Yanagizawa-Drott (2009): "The Strategic Determinants of US Human Rights Reporting: Evidence from the Cold War," Journal of the European Economic Association, 7(2-3), pp. 446-457.

Schultz, G. P. (1984): "New Coverage of Central America (Memo to The President)," Discussion paper, National Security Archives.

Stromberg, D. (1999): The Politics of Public Spending. Princeton University.

(2004a): "Mass Media Competition, Political Competition, and Public Policy," Review of Economic Studies, 71(1), pp. 265-284.

(2004b): "Radio's Impact on Public Spending," The Quarterly Journal of Economics, 119(1), pp. 189-221.

Thomas, H. (2006): Watchdogs of Democracy? The Waning Press Corps and How It Has Failed the Public. Scribner, New York.

Voeten, E. (2001): "Outside Options and the Logic of Security Council Action Source," The American Political Science Review, 95(4), pp. 845-858.

Wood, R. M., and M. Gibney (2010): "The Political Terror Scale (PTS): a Re-introduction and a Comparison to CIRI," Human Rights Quarterly, 32(2), pp. 367-400. 


\section{Appendix: proof of Lemma 1}

Proof. Let $q_{n}^{*}(N)$ be the solution to $(5)$ and $\hat{q}_{n}(N)$ be defined by (4) for a given $N$. We will show that $\hat{q}_{n}(N)-q_{n}^{*}(N) \rightarrow 0$ a.s. as $N \rightarrow \infty$, which is the formal sense in which lemma 1 holds. Let $\tilde{N}(N)$ be the number of countries that commit human rights violations. By the law of large numbers, the fraction of countries which commit human right violations, $\tilde{N}(N) / N \rightarrow 1 / 2$ a.s., as $N \rightarrow \infty$. For the rest of the proof, we drop the explicit conditioning on $N$, but $q_{n}^{*}, q_{n}, \tilde{N}$ are all understood to be functions of $N$.

The proof goes in two steps. First, we will show that out of countries that commit human rights violations, it is not optimal to distort at least half of them by more than some small $\delta$. The cost of suppressing $\hat{q}_{n}-q_{n}^{*}$ news is

$$
\begin{aligned}
T\left(\hat{q}_{n}-q_{n}^{*}\right) & \geq(p-d) m_{1}\left(\hat{q}_{n}-q_{n}^{*}\right)-\gamma\left[\frac{\left(\hat{q}_{n}\right)^{2}}{2}-\frac{\left(q_{n}^{*}\right)^{2}}{2}\right] \\
& =\left(\hat{q}_{n}-q_{n}^{*}\right)\left[(p-d) m_{1}-\frac{\gamma}{2}\left(\hat{q}_{n}+q_{n}^{*}\right)\right] \\
& =\left(\hat{q}_{n}-q_{n}^{*}\right)\left[(p-d) m_{1}-\frac{\gamma}{2}\left(2 \hat{q}_{n}+\left(q_{n}^{*}-\hat{q}_{n}\right)\right)\right] \\
& =\frac{\gamma}{2}\left(\hat{q}_{n}-q_{n}^{*}\right)^{2}
\end{aligned}
$$

where in the third equality we used the fact that $\hat{q}_{n}$ solves (4). Pick some $\delta>0$. If $\hat{q}_{n}-q_{n}^{*}>\delta$, then $T\left(\hat{q}_{n}-q_{n}^{*}\right) \geq \frac{\gamma}{2} \delta^{2}$. Suppose there are at least $\tilde{N} / 2$ countries which committed human rights violations and for which the equilibrium distortion is $\hat{q}_{n}-q_{n}^{*}>\delta$. Then the total cost of bribing,

$\sum_{n=1}^{N+1} T\left(\hat{q}_{n}-q_{n}\right) \geq \frac{\tilde{N} \gamma}{4} \delta^{2}$. Since the total benefit of remaining in power is $R$, if $N$ (and hence $\left.\tilde{N}\right)$ is sufficiently large, then $\frac{\gamma}{4} \tilde{N} \delta^{2}>R$ and the sum of bribes exceeds the total benefit of remaining in power, which is suboptimal. Therefore, for at least $\tilde{N} / 2$ countries in equilibrium $\hat{q}_{n}-q_{n}^{*}<\delta$.

Now we can show that it is not optimal to distort any country not on the UNSC by more than $\delta$. Without any loss of generality, we show that it is not optimal to do so for country 1 because the optimal news distortion for this country should satisfy

$$
\begin{aligned}
& {\left[s\left(\left\{q_{n}^{*}\right\}_{n=1}^{N+1}\right) \theta_{U S}+\left(1-s\left(\left\{q_{n}^{*}\right\}_{n=1}^{N+1}\right)\right) \frac{1}{2}\right] R-T\left(\hat{q}_{1}-q_{1}^{*}\right) } \\
\geq & {\left[s\left(\hat{q}_{1},\left\{q_{n}^{*}\right\}_{n=2}^{N+1}\right) \theta_{U S}+\left(1-s\left(\hat{q}_{1},\left\{q_{n}^{*}\right\}_{n=2}^{N+1}\right)\right) \frac{1}{2}\right] R, }
\end{aligned}
$$


where the right hand side represents benefits of not distorting country 1 at all, and the left hand side is the benefit from distorting. Alternatively, it can be written as

$$
\begin{aligned}
& {\left[s\left(\left\{q_{n}^{*}\right\}_{n=1}^{N+1}\right)-s\left(\hat{q}_{1},\left\{q_{n}^{*}\right\}_{n=2}^{N+1}\right)\right]\left(\theta_{U S}-\frac{1}{2}\right) R } \\
\geq & T\left(\hat{q}_{1}-q_{1}^{*}\right) .
\end{aligned}
$$

For any combination of news coverage $\left\{q_{n}\right\}$, the fraction of uninformed agents in group 1 is given by

$$
\begin{aligned}
s\left(\left\{q_{n}\right\}_{n=1}^{N+1}\right)= & {\left[1-\left(1-\max \left\{q_{1}-p, 0\right\}\right) \times \ldots \times\left(1-\max \left\{q_{N+1}-p, 0\right\}\right)\right] m_{1} } \\
& +\left(q_{N+1}-p\right)\left(m_{1}+m_{2}\right) .
\end{aligned}
$$

Pick $\delta<\frac{1}{\gamma}(p-d) m_{1}$. From the first step, if $N$ is sufficiently large, there are $\tilde{N} / 2$ countries for which $1 \geq q_{n}^{*}-p \geq \hat{q}-p-\delta>0$ where $\hat{q}=\frac{1}{\gamma}(p-d) m_{1}$. Therefore, for any $q_{1}, s\left(q_{1},\left\{q_{n}^{*}\right\}_{n=2}^{N+1}\right) \geq$ $\left[1-(1-(\hat{q}-p-\delta))^{\tilde{N} / 2}\right] m_{1}$ which goes to $m_{1}$ as $\tilde{N} \rightarrow \infty$. This implies that $s\left(\left\{q_{n}^{*}\right\}_{n=1}^{N+1}\right)-$ $s\left(\hat{q}_{1},\left\{q_{n}^{*}\right\}_{n=2}^{N+1}\right) \rightarrow 1$ and hence from $(7) \hat{q}_{1}-q_{1}^{*} \rightarrow 0$ as $N \rightarrow \infty$. 


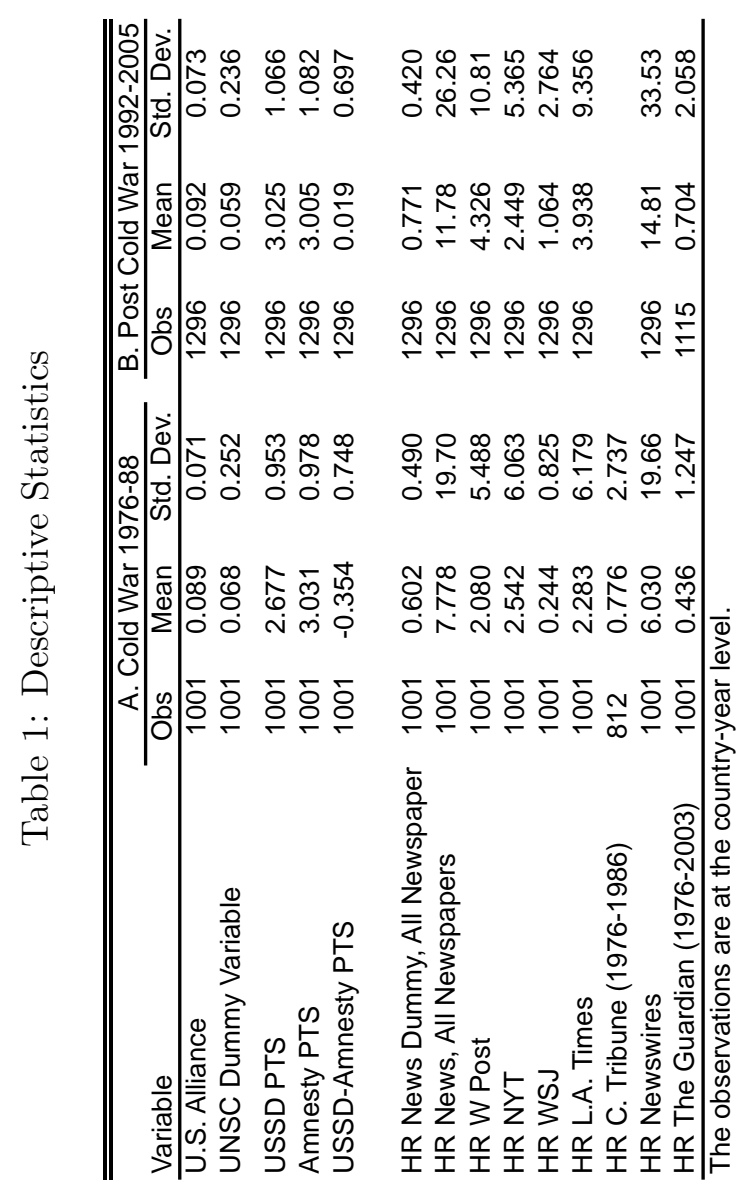




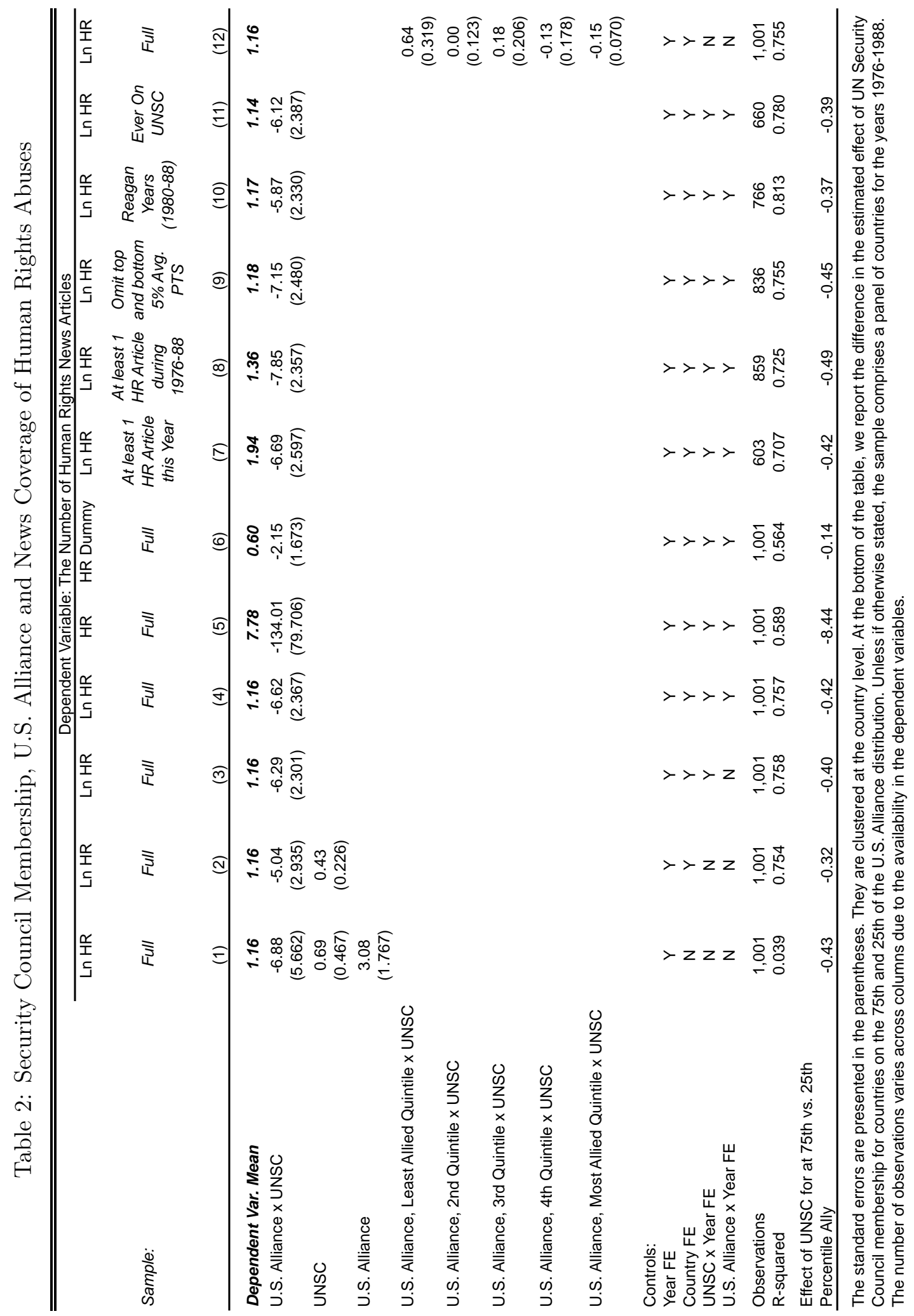




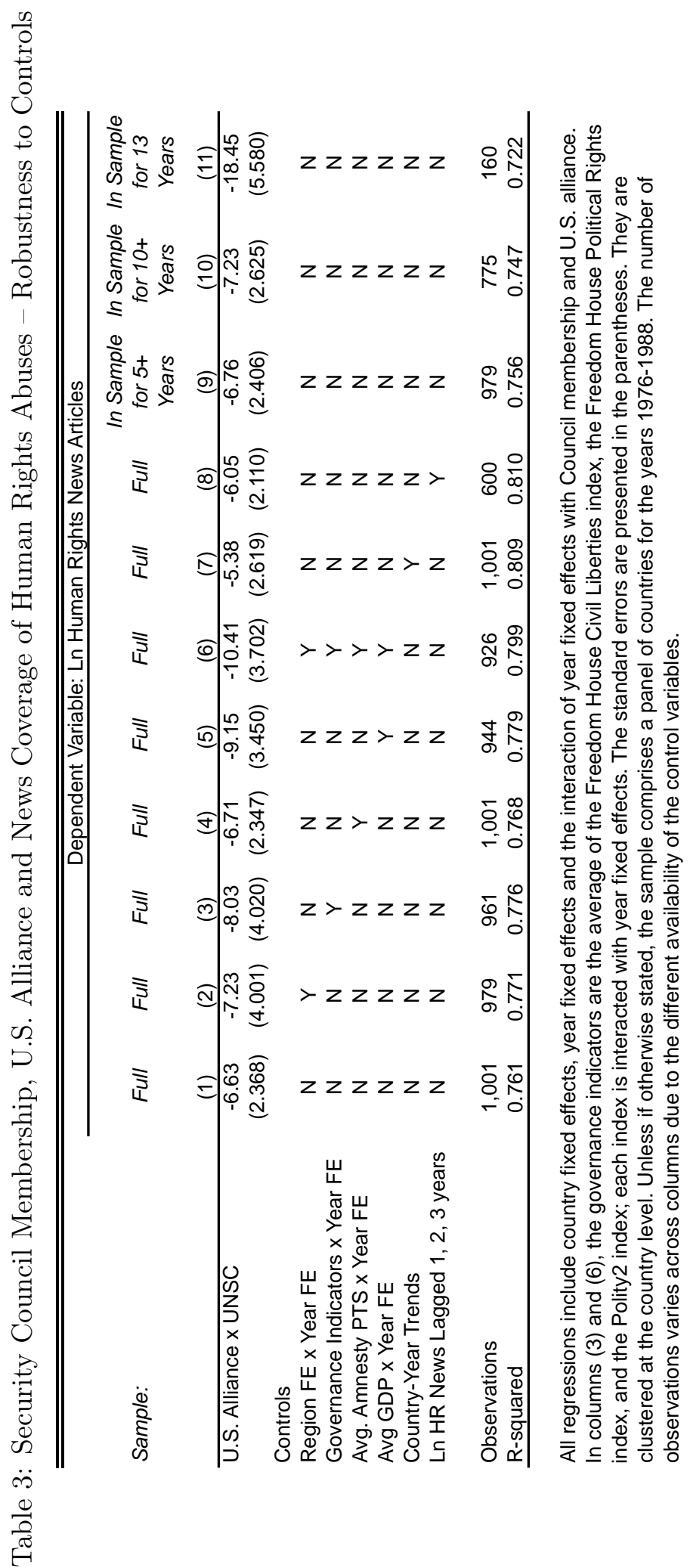




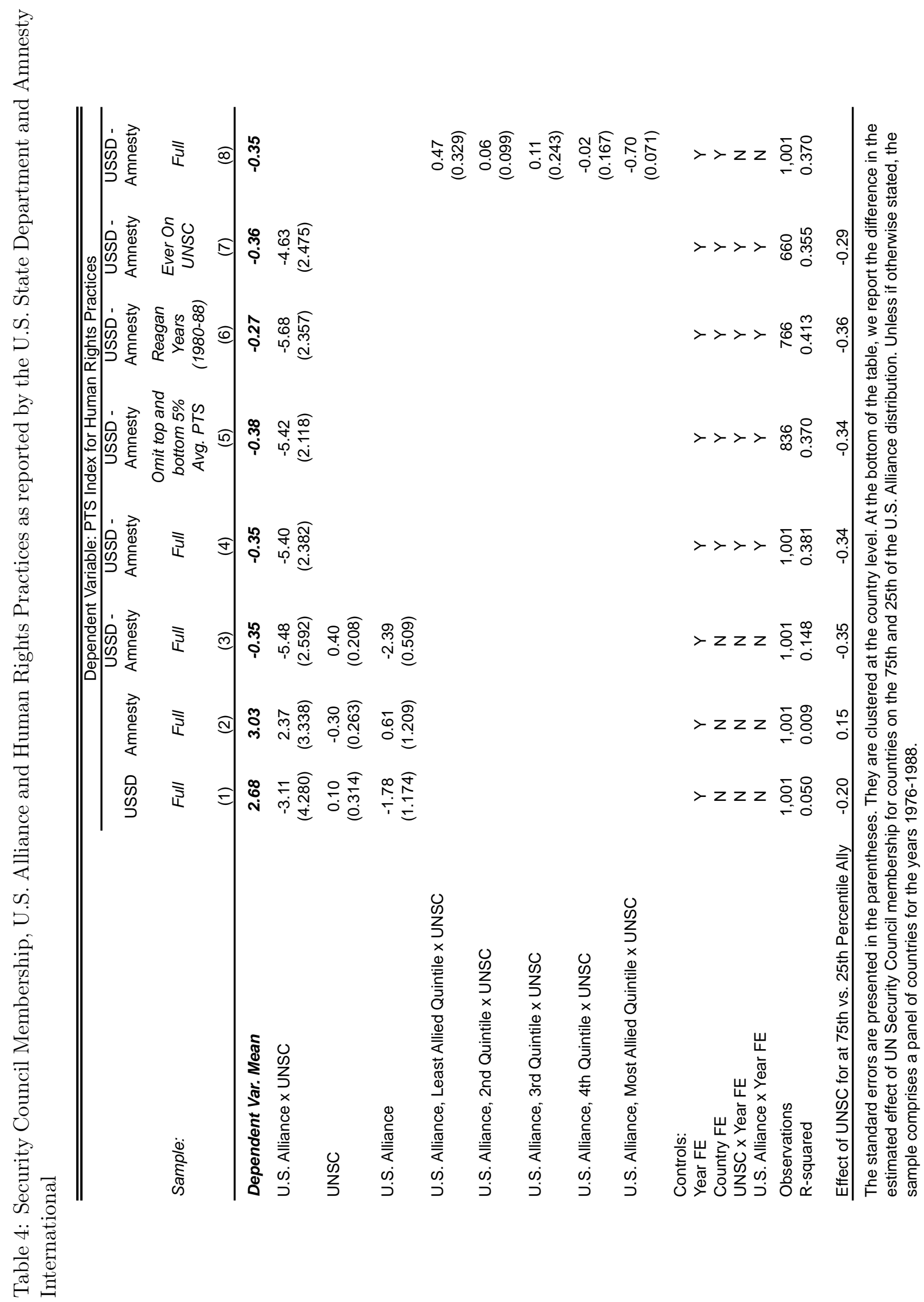




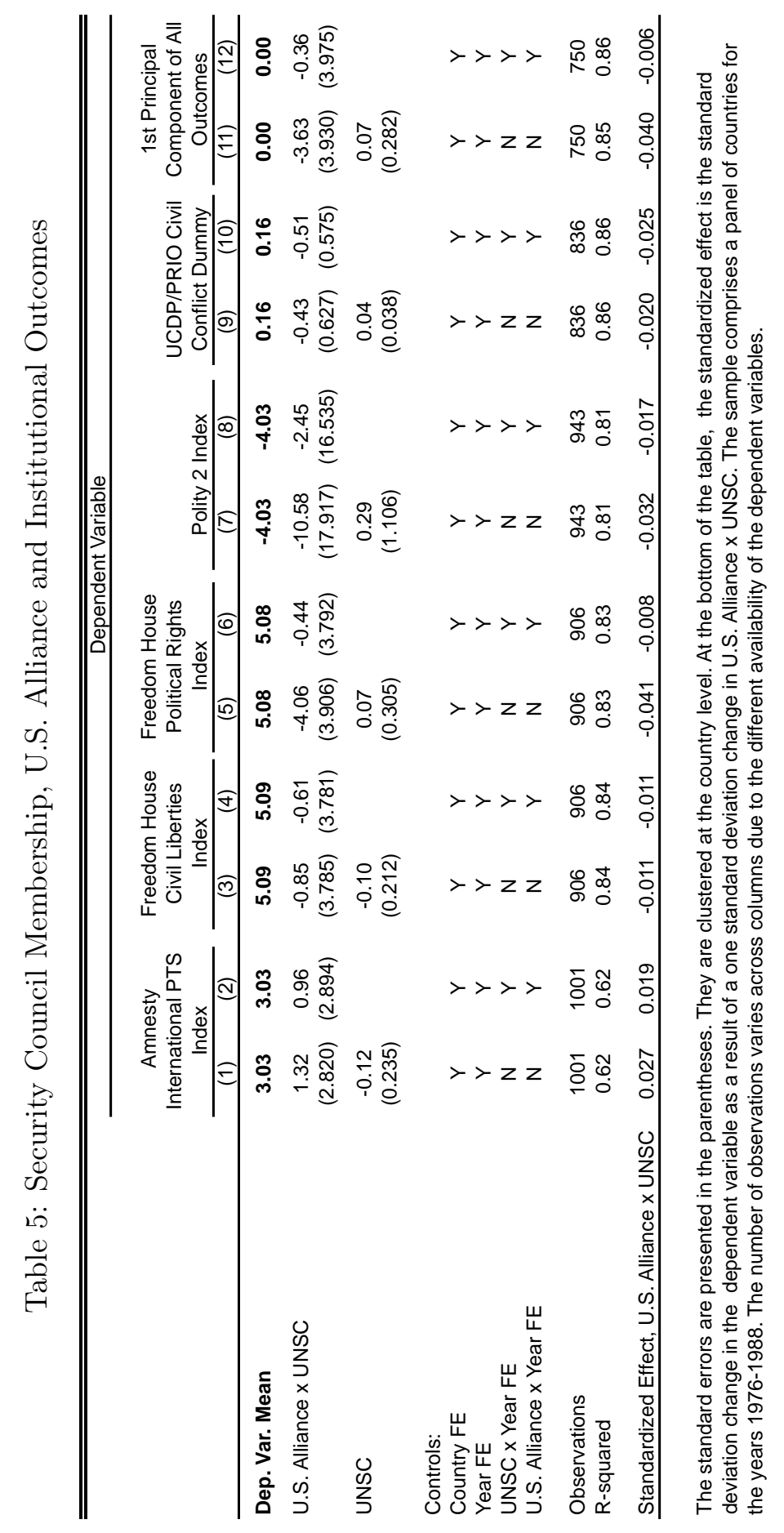




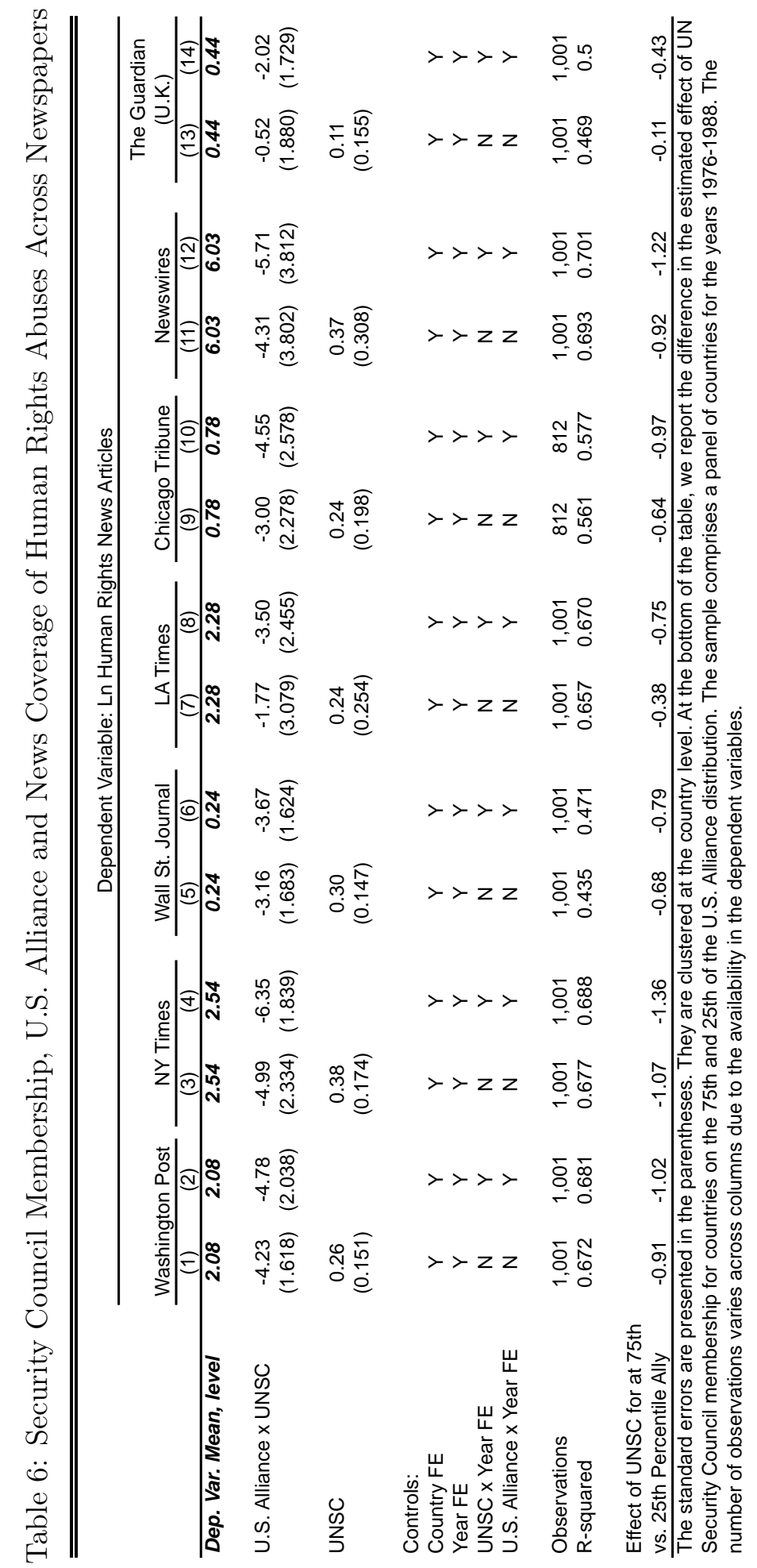


Figure 1: Coefficients of Years Since Security Council Membership Dummy Variables $\times$ U.S. Alliance on News Coverage

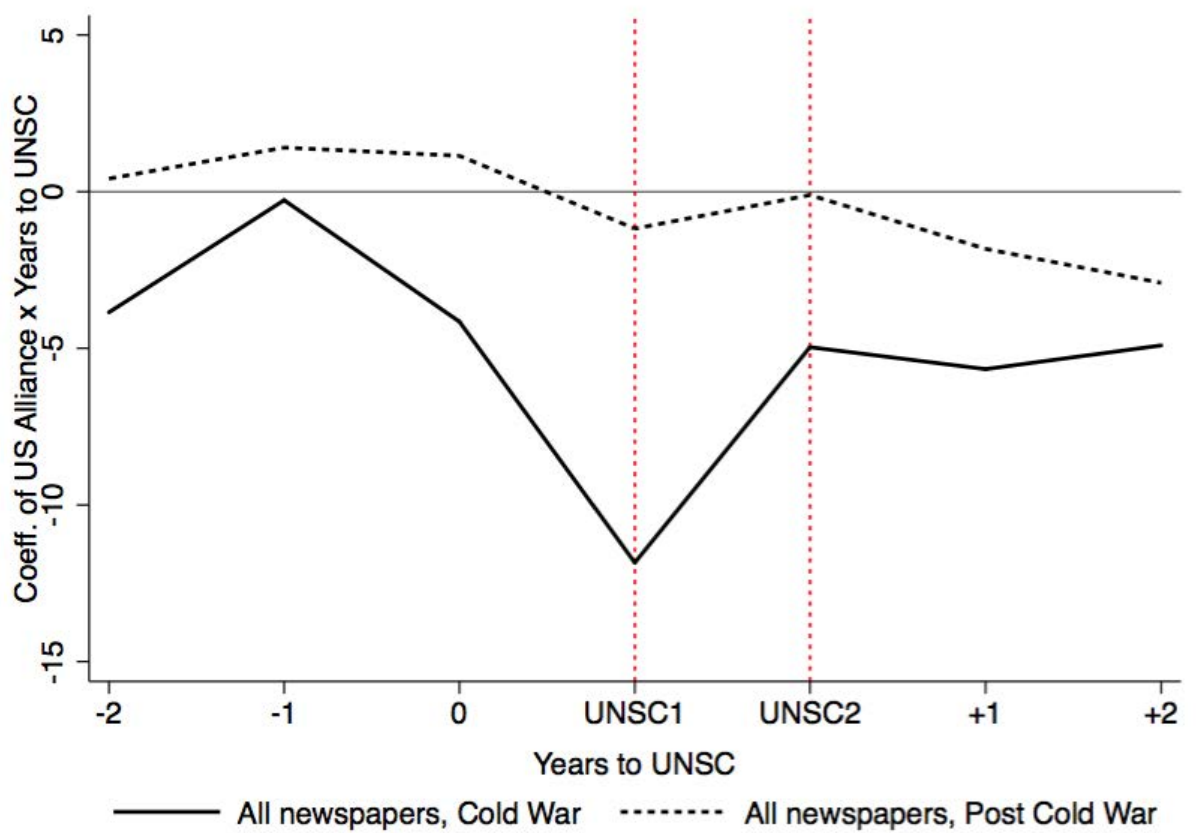

(a) Ln Number of Articles on Human Rights, Cold War and Post-Cold War Periods

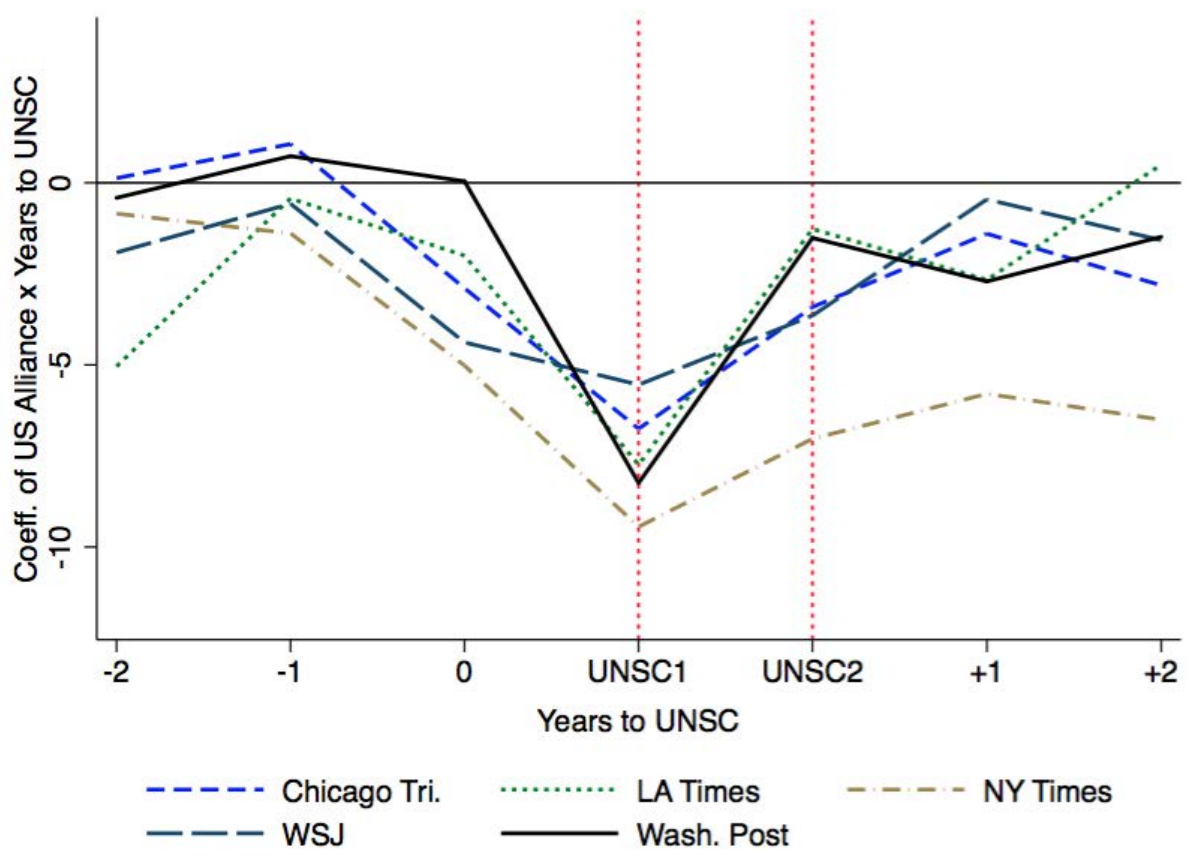

(b) Ln Number of Articles on Human Rights by Paper, Cold War 
Figure 2: Coefficients of Years Since Security Council Membership Dummy Variables $\times$ U.S. Alliance on Human Rights Practices

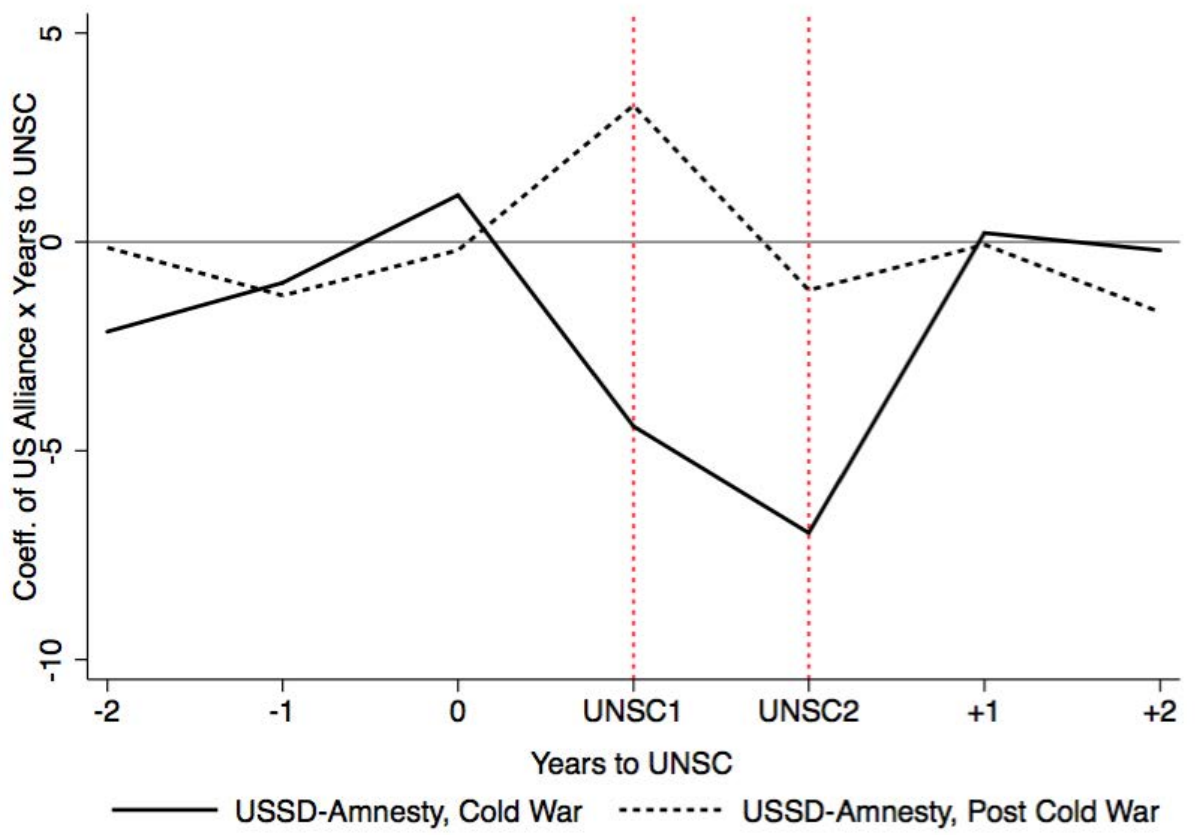

(a) USSD - Amnesty PTS, Cold War and Post-Cold War Periods

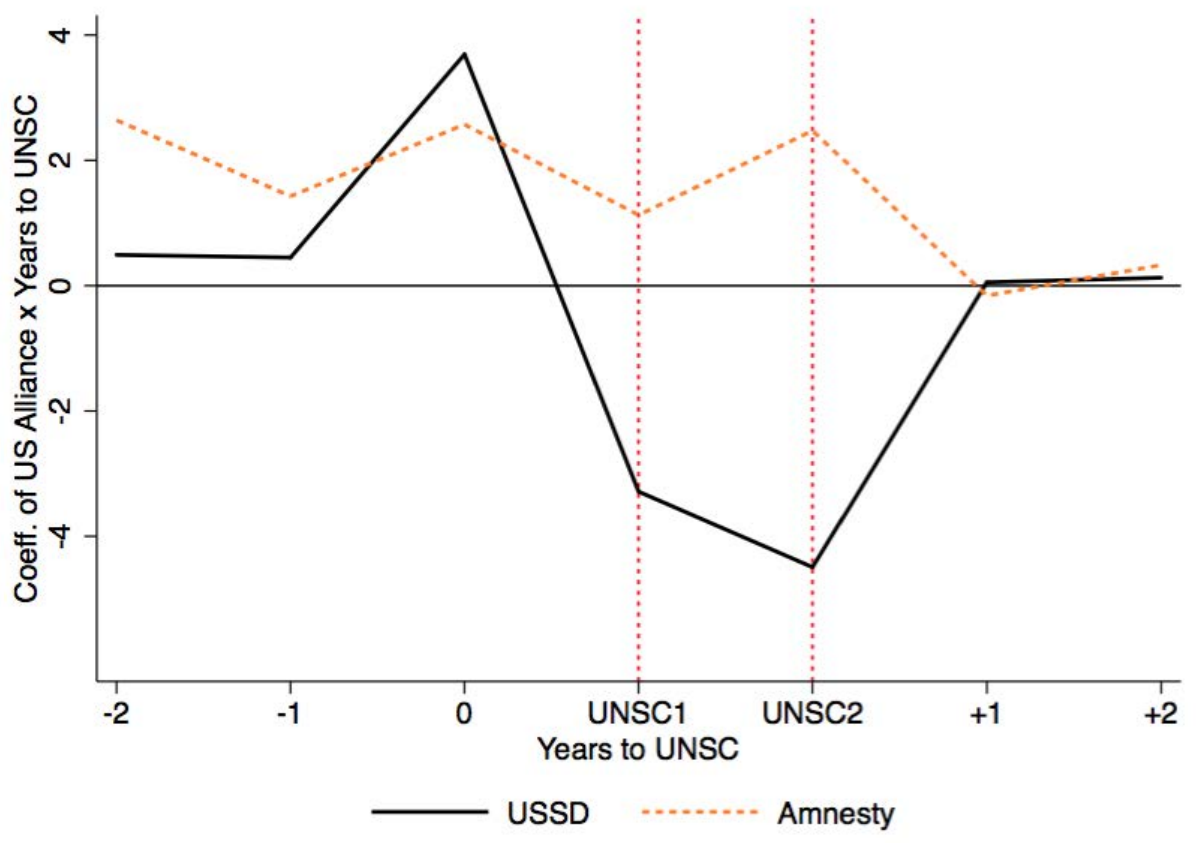

(b) USSD PTS and Amnesty PTS, Cold War Only 
Figure 3: The Correlates of Government Distortion

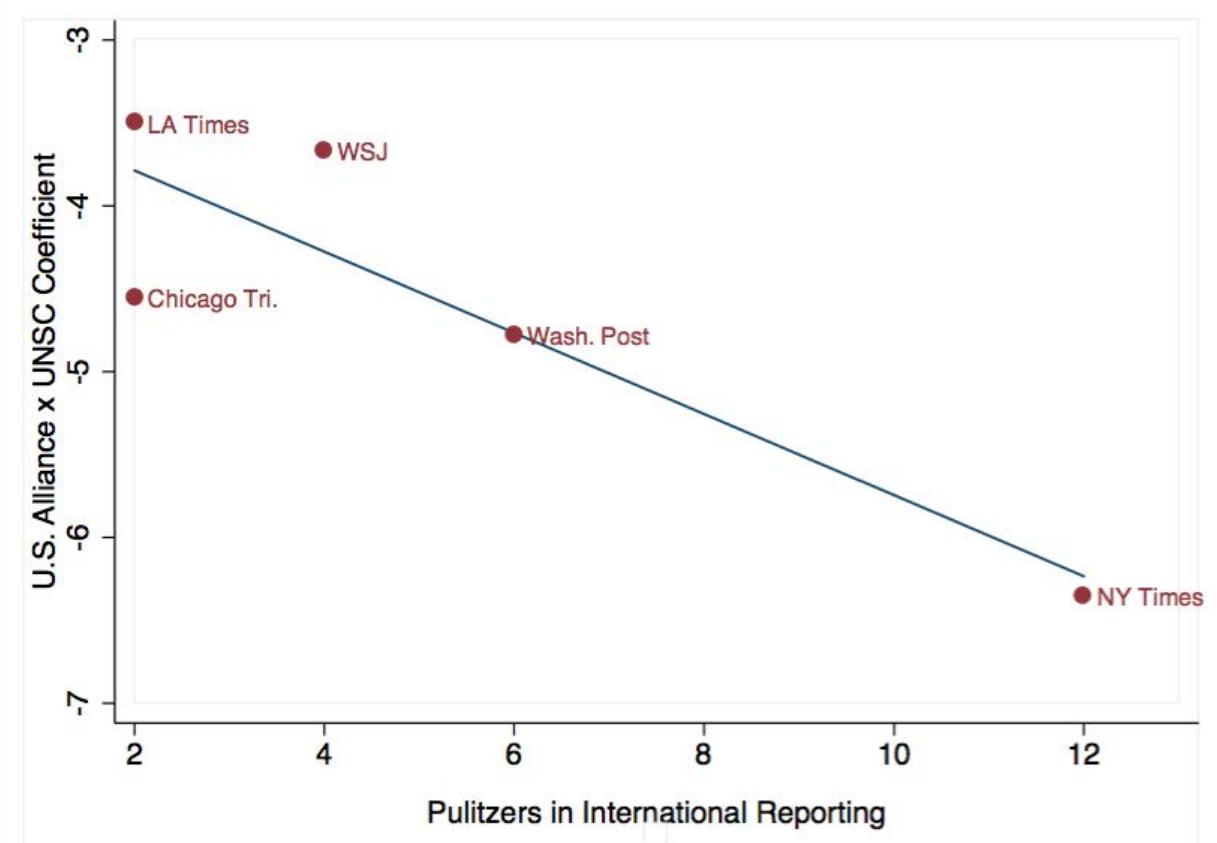

(a) Estimated Distortion and Quality as measured by the number of Pulitzer Prizes in International Reporting 1976-2005

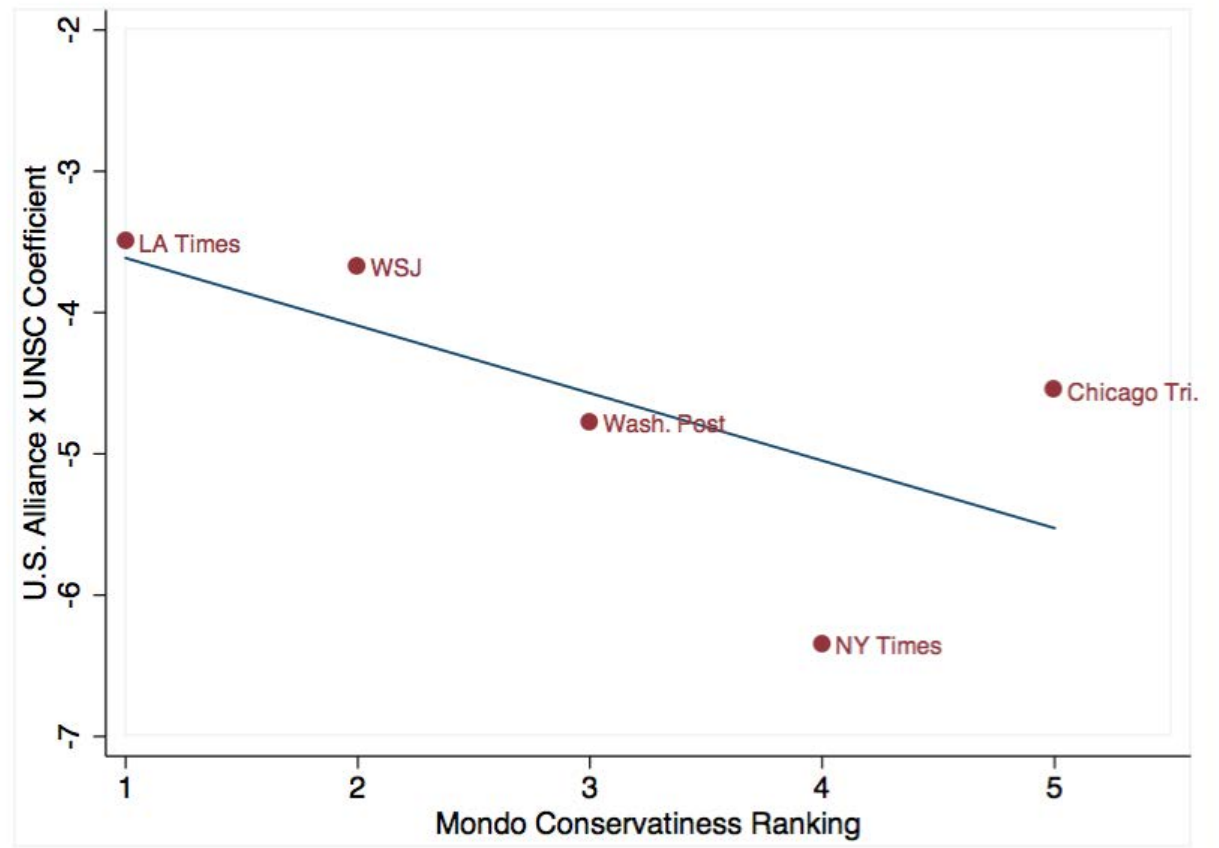

(b) Estimated Distortion and Reader Attitude as measured by the Mondo Conservativeness Rating in 2008 
Table A.1: UN Security Council Members

\begin{tabular}{|c|c|c|c|c|c|c|c|}
\hline \multicolumn{4}{|c|}{ Cold War 1976-1988 } & \multicolumn{4}{|c|}{ Post Cold War 1992-2002 } \\
\hline Year & Country & Year & Country & Year & Country & Year & Country \\
\hline 1976 & Benin & 1983 & Zaire/DRC & 1992 & Cape Verde & 1999 & Argentina \\
\hline 1976 & Guyana & 1983 & Guyana & 1992 & Ecuador & 1999 & Brazil \\
\hline 1976 & Libya & 1983 & Jordan & 1992 & Hungary & 1999 & Gabon \\
\hline 1976 & Pakistan & 1983 & Malta & 1992 & India & 1999 & Gambia, The \\
\hline 1976 & Panama & 1983 & Nicaragua & 1992 & Venezuela & 1999 & Malaysia \\
\hline 1976 & Romania & 1983 & Pakistan & 1992 & Zimbabwe & 2000 & Argentina \\
\hline 1976 & Tanzania & 1983 & Poland & 1993 & Brazil & 2000 & Bangladesh \\
\hline 1977 & Benin & 1983 & Togo & 1993 & Cape Verde & 2000 & Jamaica \\
\hline 1977 & India & 1983 & Zimbabwe & 1993 & Djibouti & 2000 & Malaysia \\
\hline 1977 & Libya & 1984 & Burkina Faso & 1993 & Hungary & 2000 & Mali \\
\hline 1977 & Mauritius & 1984 & Egypt, Arab Rep. & 1993 & Pakistan & 2000 & Tunisia \\
\hline 1977 & Pakistan & 1984 & India & 1993 & Venezuela & 2001 & Bangladesh \\
\hline 1977 & Panama & 1984 & Malta & 1994 & Argentina & 2001 & Colombia \\
\hline 1977 & Romania & 1984 & Nicaragua & 1994 & Brazil & 2001 & Jamaica \\
\hline 1977 & Venezuela & 1984 & Pakistan & 1994 & Djibouti & 2001 & Mali \\
\hline 1978 & Bolivia & 1984 & Peru & 1994 & Nigeria & 2001 & Mauritius \\
\hline 1978 & Gabon & 1984 & Zimbabwe & 1994 & Oman & 2001 & Tunisia \\
\hline 1978 & India & 1985 & Burkina Faso & 1994 & Pakistan & 2002 & Bulgaria \\
\hline 1978 & Mauritius & 1985 & Egypt, Arab Rep. & 1994 & Rwanda & 2002 & Cameroon \\
\hline 1978 & Nigeria & 1985 & India & 1995 & Argentina & 2002 & Colombia \\
\hline 1978 & Venezuela & 1985 & Madagascar & 1995 & Botswana & 2002 & Guinea \\
\hline 1979 & Bangladesh & 1985 & Peru & 1995 & Honduras & 2002 & Mauritius \\
\hline 1979 & Bolivia & 1985 & Thailand & 1995 & Indonesia & 2002 & Mexico \\
\hline 1979 & Gabon & 1985 & Trinidad and Tobago & 1995 & Nigeria & 2002 & Syrian Arab Republic \\
\hline 1979 & Jamaica & 1986 & Bulgaria & 1995 & Oman & 2003 & Angola \\
\hline 1979 & Nigeria & 1986 & Congo, Rep. & 1995 & Rwanda & 2003 & Bulgaria \\
\hline 1979 & Zambia & 1986 & Ghana & 1996 & Botswana & 2003 & Cameroon \\
\hline 1980 & Bangladesh & 1986 & Madagascar & 1996 & Chile & 2003 & Chile \\
\hline 1980 & Jamaica & 1986 & Thailand & 1996 & Egypt & 2003 & Guiinea \\
\hline 1980 & Mexico & 1986 & Trinidad and Tobago & 1996 & Guinea-Bissau & 2003 & Mexico \\
\hline 1980 & Niger & 1986 & Venezuela & 1996 & Honduras & 2003 & Pakistan \\
\hline 1980 & Philippines & 1987 & Argentina & 1996 & Indonesia & 2003 & Syrian Arab Republic \\
\hline 1980 & Tunisia & 1987 & Bulgaria & 1996 & Poland & 2004 & Algeria \\
\hline 1980 & Zambia & 1987 & Congo, Rep. & 1997 & Chile & 2004 & Angola \\
\hline 1981 & Mexico & 1987 & Ghana & 1997 & Costa Rica & 2004 & Benin \\
\hline 1981 & Niger & 1987 & Venezuela & 1997 & Egypt & 2004 & Brazil \\
\hline 1981 & Panama & 1987 & Zambia & 1997 & Guinea-Bissau & 2004 & Chile \\
\hline 1981 & Philippines & 1988 & Algeria & 1997 & Kenya & 2004 & Pakistan \\
\hline 1981 & Tunisia & 1988 & Argentina & 1997 & Poland & 2004 & Phillipines \\
\hline 1981 & Uganda & 1988 & Brazil & 1998 & Brazil & 2004 & Romania \\
\hline 1982 & Zaire/DRC & 1988 & Nepal & 1998 & Costa Rica & 2005 & Algeria \\
\hline 1982 & Guyana & 1988 & Senegal & 1998 & Gabon & 2005 & Benin \\
\hline 1982 & Jordan & 1988 & Yugoslavia/FYR & 1998 & Gambia, The & 2005 & Brazil \\
\hline 1982 & Panama & 1988 & Zambia & 1998 & Kenya & 2005 & Phillipines \\
\hline 1982 & Poland & & & & & 2005 & Romania \\
\hline 1982 & Togo & & & & & & \\
\hline 1982 & Uganda & & & & & & \\
\hline
\end{tabular}




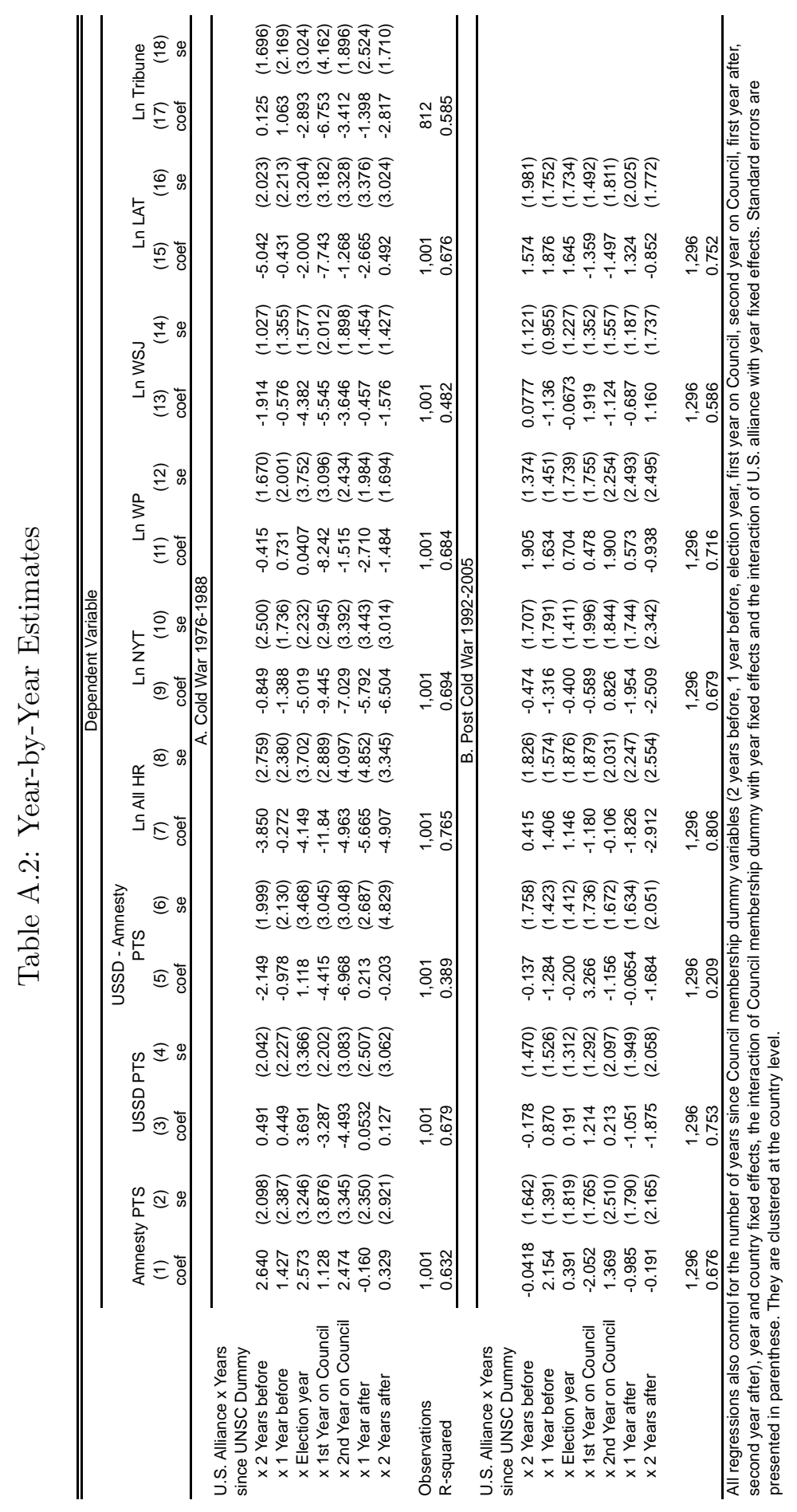


Table A.3: Pulitzer Prizes and Reader Attitude Ratings

\begin{tabular}{ccc}
\hline \hline Newspaper & $\begin{array}{c}\text { \# of Pulitzer Prizes in International } \\
\text { News Reporting }\end{array}$ & $\begin{array}{c}\text { Mondo Conservativeness } \\
\text { Ranking (2008) }\end{array}$ \\
\hline NY Times & 12 & 4 \\
Wash. Post & 6 & 3 \\
WSJ & 4 & 2 \\
Chicago Tri. & 2 & 1 \\
LA Times & 2 & 5 \\
\hline
\end{tabular}

Notes: Coefficient of UNSC $\times$ U.S. Alliance is from the baseline specification. See Table 5. 
Figure A.1: The Fraction of Divided Votes and Votes with the United States in the UN General Assembly

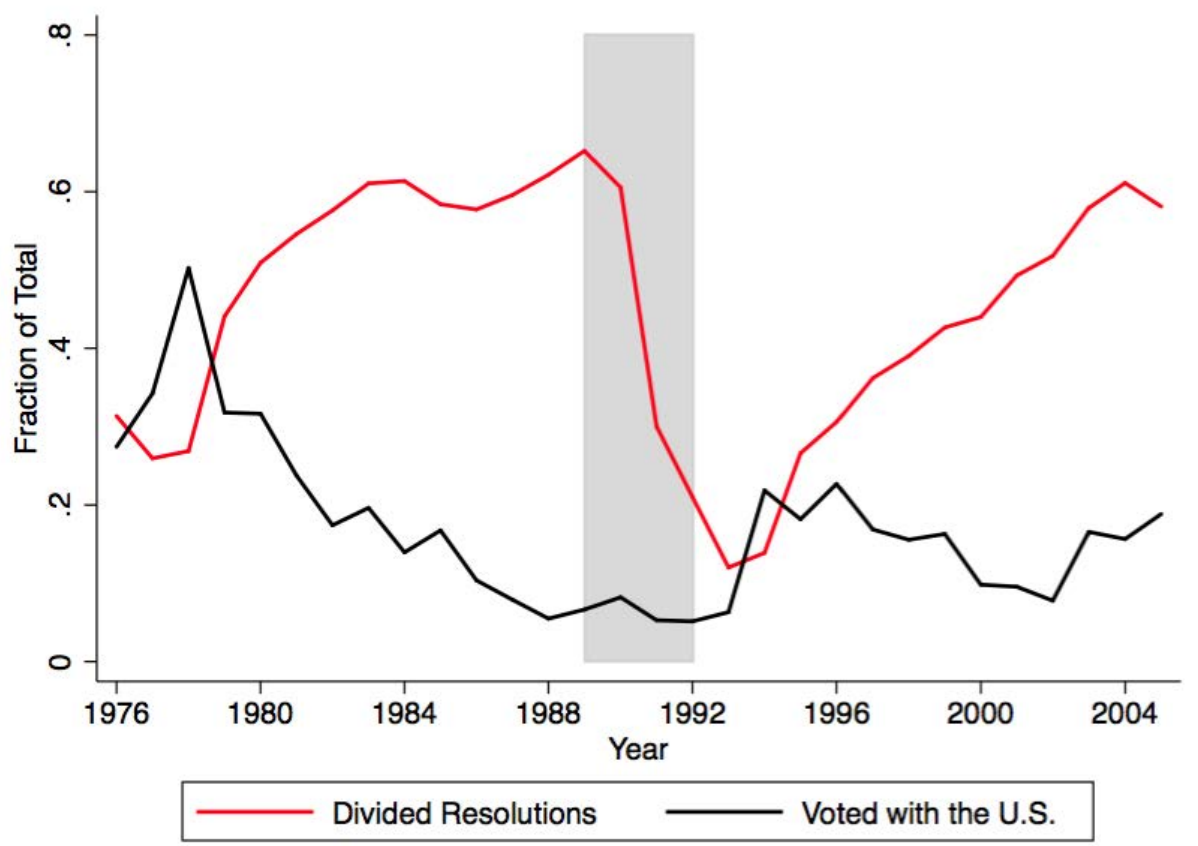

Figure A.2: The Number of Newspaper Articles on Human Rights Abuses for each Day since the Release of U.S. State Department and Amnesty Reports (Averages across years, 1976-1988)

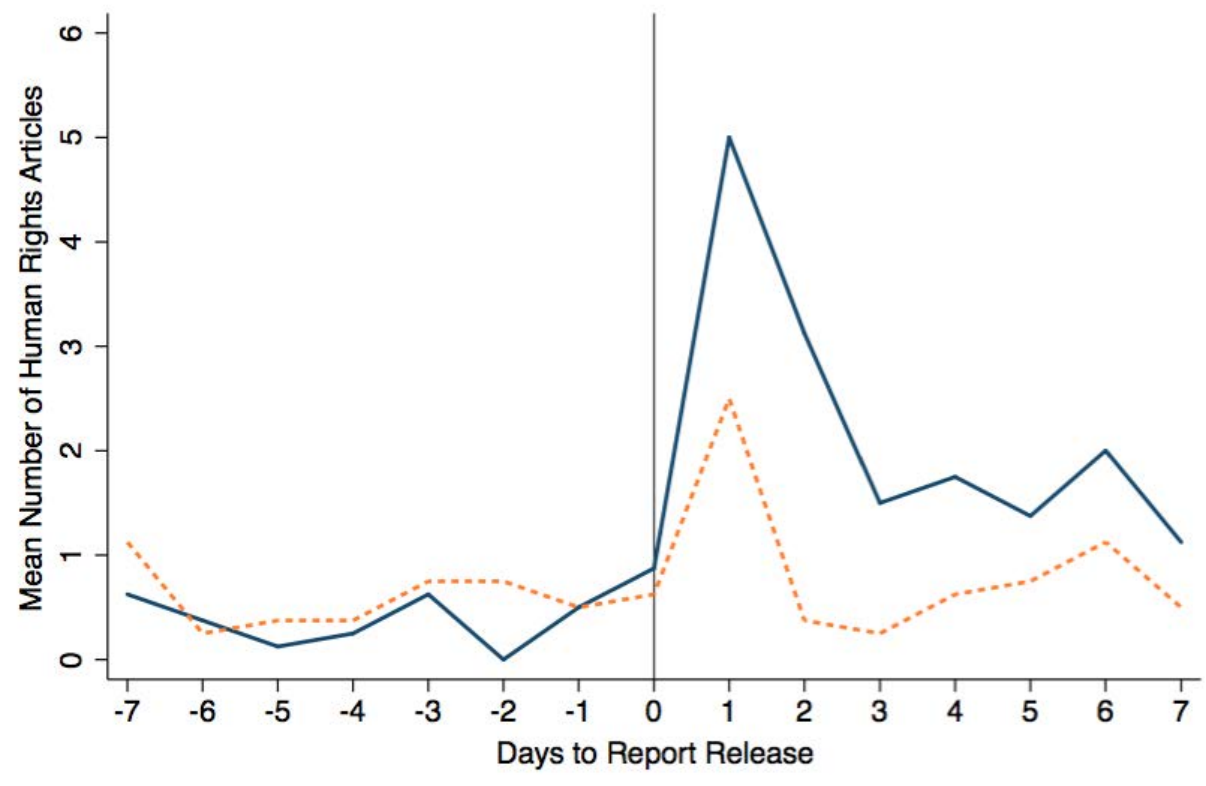


Figure A.3: The Effects of U.S. Alliance $\times$ Years Since Council Membership Dummy Variables with 95\% Confidence Intervals, Cold War (1976-88)

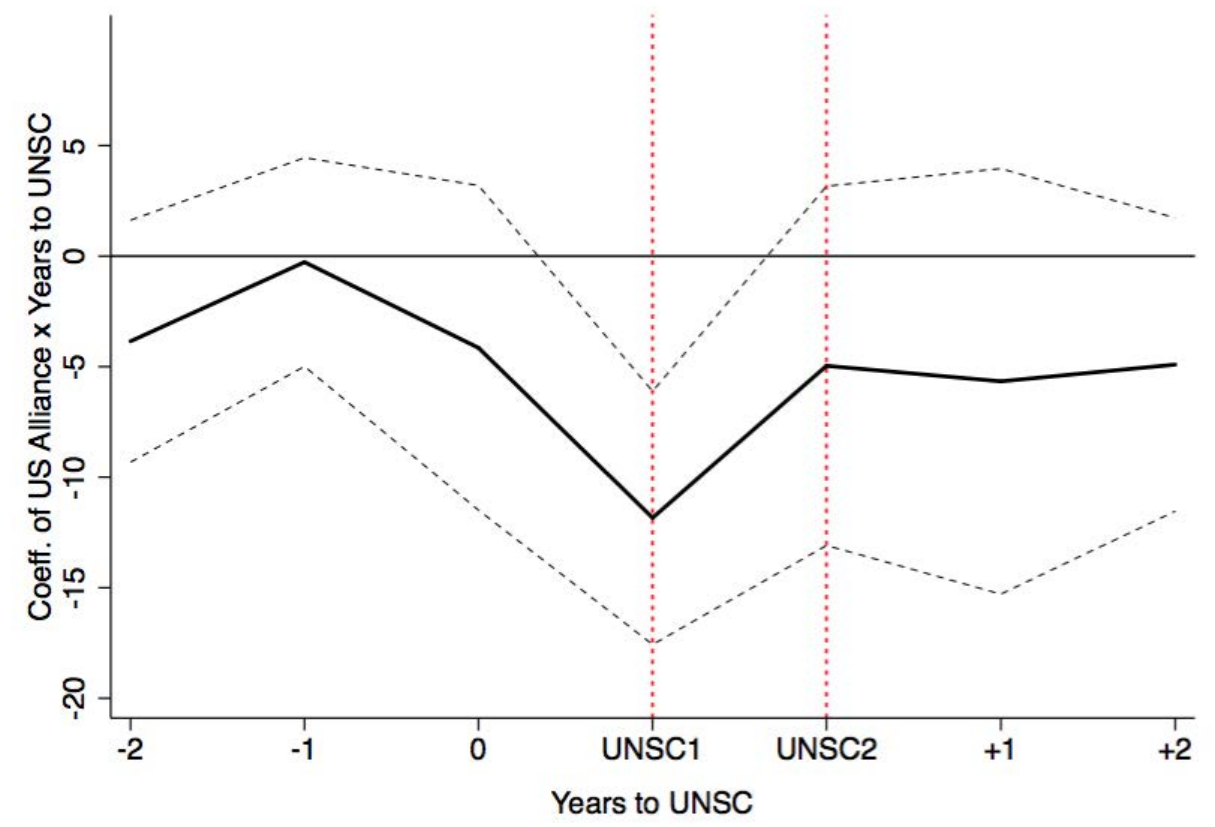

(a) News Coverage (Ln Number of Articles on Human Rights)

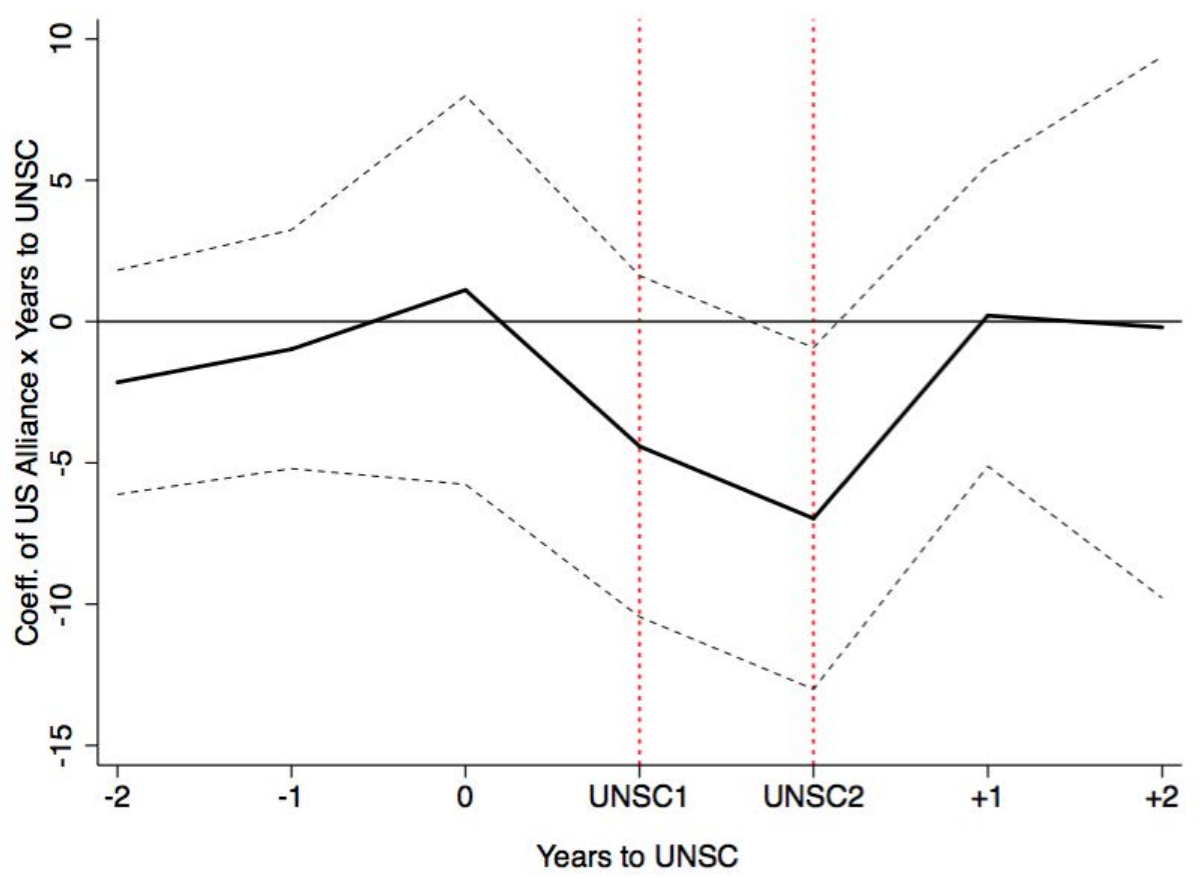

(b) Human Rights Practices (USSD PTS - Amnesty PTS) 